\title{
Spatial variability of herbicide mobilisation and transport at catchment scale: insights from a field experiment
}

\author{
T. Doppler ${ }^{1,2}$, L. Camenzuli ${ }^{1,2}$, G. Hirzel ${ }^{1,2}$, M. Krauss ${ }^{1, *}$, A. Lück ${ }^{1}$, and C. Stamm ${ }^{1}$ \\ ${ }^{1}$ Swiss Federal Institute of Aquatic Science and Technology (Eawag), Dübendorf, Switzerland \\ ${ }^{2}$ Swiss Federal Institute of Technology (ETH), Zürich, Switzerland \\ * now at: UFZ - Helmholtz Centre for Environmental Research, Leipzig, Germany
}

Correspondence to: T. Doppler (tobias.doppler@eawag.ch)

Received: 13 February 2012 - Published in Hydrol. Earth Syst. Sci. Discuss.: 22 February 2012 Revised: 14 May 2012 - Accepted: 6 June 2012 - Published: 6 July 2012

\begin{abstract}
During rain events, herbicides can be transported from their point of application to surface waters, where they may harm aquatic organisms. Since the spatial pattern of mobilisation and transport is heterogeneous, the contributions of different fields to the herbicide load in the stream may vary considerably within one catchment. Therefore, the prediction of contributing areas could help to target mitigation measures efficiently to those locations where they reduce herbicide pollution the most.

Such spatial predictions require sufficient insight into the underlying transport processes. To improve the understanding of the process chain of herbicide mobilisation on the field and the subsequent transport through the catchment to the stream, we performed a controlled herbicide application on corn fields in a small agricultural catchment (ca. $\left.1 \mathrm{~km}^{2}\right)$ with intensive crop production in the Swiss Plateau. Water samples were collected at different locations in the catchment (overland flow, tile drains and open channel) for two months after application in 2009, with a high temporal resolution during rain events. We also analysed soil samples from the experimental fields and measured discharge, groundwater level, soil moisture and the occurrence of overland flow at several locations. Several rain events with varying intensities and magnitudes occurred during the study period. Overland flow and erosion were frequently observed in the entire catchment. Infiltration excess and saturation excess overland flow were both observed. However, the main herbicide loss event was dominated by infiltration excess.

Despite the frequent and wide-spread occurrence of overland flow, most of this water did not reach the channel directly, but was retained in small depressions in the catchment.
\end{abstract}

From there, it reached the stream via macropores and tile drains. Manholes of the drainage system and storm drains for road and farmyard runoff acted as additional shortcuts to the stream.

Although fast flow processes such as overland and macropore flow reduce the influence of the herbicide's chemical properties on transport due to short travel times, sorption properties influenced the herbicide transfer from ponding overland flow to tile drains (macropore flow). However, no influence of sorption was observed during the mobilisation of the herbicides from soil to overland flow. These observations on the role of herbicide properties contradict previous findings to some degree. Furthermore, they demonstrate that valuable insight can be gained by making spatially detailed observations along the flow paths.

\section{Introduction}

In modern agriculture, a wide variety of pesticides ${ }^{1}$ is used to increase crop productivity. Pesticides encompass a broad range of chemicals. They are used to control weeds, to fight plant diseases, insects, arachnids and other pests. Pesticides can enter the water system, where they can harm aquatic organisms even in low concentrations. Small streams in catchments with intensive crop production are especially at risk (Liess and Schulz, 1999), as diffuse pollution from

\footnotetext{
${ }^{1}$ We use the term pesticides when we refer to the full range of chemicals encompassing all plant protection agents (herbicides, fungicides, insecticides, etc.). The term herbicides is used when we specifically refer to herbicides.
} 
agricultural fields causes major inputs to the stream in these areas (Leu et al., 2010). Pesticides mainly enter surface waters during rain events, when they are mobilised and transported with fast runoff (Thurman et al., 1991). Under Swiss conditions, the two most important input pathways in this context are overland flow and, when subsurface drains are present, preferential flow to the drainage system. The pathway to groundwater and exfiltration into streams as baseflow is of little importance for most pesticides due to sorption and degradation (e.g. Thurman et al., 1991).

In several cases it has been shown that herbicide loss rates (relative to the applied amount) from different fields within a given catchment can differ by over an order of magnitude (Gomides Freitas et al., 2008; Leu et al., 2004b, 2005; Louchart et al., 2001). This implies that a relatively small proportion of a catchment can cause the major part of surface water pollution with herbicides. The same has been observed for diffuse pollution of surface waters with phosphorus (Pionke et al., 1996, 2000). These observations did not surprise hydrologists. It was recognized in the 1960s and 1970s that not all areas contribute to storm runoff (Betson, 1964; Dunne and Black, 1970) and that diffuse pollution should be expected from only a limited fraction of a catchment (Freeze, 1974). The areas that contribute a large fraction of the pollution load are called critical source areas (CSAs) or contributing areas (Pionke et al., 1996).

The insight that not all parts of a catchment have the same relevance for diffuse pollution offers efficient mitigation options, because actions on a small proportion of the area can strongly reduce the substance input to the stream. An area has to fulfil three conditions to become a critical source area: (1) The area needs to be a substance source, e.g. the areas where pesticides are applied. (2) The area has to be hydrologically active, i.e. the relevant mobilisation and transport processes occur in the area. For pesticides, these are overland flow and/or macropore flow. (3) The area has to be connected to the stream; for pesticides this implies that the overland flow or macropore flow with the mobilised pesticides has to reach the stream either directly or via the drainage system.

The spatial extent of the CSAs $\left(A_{\mathrm{CSA}}\right)$ can be interpreted as the spatial intersection of the areas of a catchment where each condition is fulfilled:

$A_{\mathrm{CSA}}=A_{\text {source }} \cap A_{\text {active }} \cap A_{\text {connect }}$

with $A_{\text {source }}$ representing the source area of a given compound, $A_{\text {active }}$ the hydrologically active area, and $A_{\text {connect }}$ the part of the catchment in direct connection to the stream network. For pesticides, $A_{\text {source }}$ depends on the pesticide applications and is not a property of the field per se. Every crop production field is a potential source area even though the pesticide applications change with crop rotation. However, the compound properties can modify $A_{\text {source }}$ in space and time. Degradation and sorption both determine the amount of substance that is available for transport at the time of rainfall (Louchart et al., 2001). If there was substantial spatial variability in degradation rates and/or sorption of pesticides to soil, these properties may affect the spatial CSA distribution. Earlier studies in the Swiss Plateau (Leu et al., 2004b; Stamm et al., 2004) indicate, however, that degradation rates and sorption coefficients do not vary strongly between fields in a catchment and could not account for observed spatial differences in herbicide loss rates. Under these conditions, and under the assumption that the areas of pesticide application are known, the CSA delineation is reduced to a hydrological problem involving the prediction of $A_{\text {active }}$ and $A_{\text {connect }}$.

For pesticide transport, the relevant flow components are fast flow like surface runoff and preferential flow to tile drains. Hence, $A_{\text {active }}$ is determined by the spatial extent of areas where these processes are generated in relevant amounts. Two different processes can lead to overland flow. Horton (1933) described the occurrence of infiltration excess overland flow, where rain intensity exceeds the infiltration capacity of the soil. In contrast, saturation excess overland flow occurs when the soil is saturated from below until the water table reaches the surface (Dunne and Black, 1970). Saturation excess overland flow usually dominates in humid climate and in well vegetated catchments (Anderson and Burt, 1978; Dunne and Black, 1970; Moore et al., 1976). Consequently, saturation excess overland flow appears to dominate phosphorus transport to surface waters in agricultural areas in humid climates (Easton et al., 2008; Lyon et al., 2006). Infiltration excess overland flow is rather the dominant process in arid and semiarid climate (e.g. Goodrich et al., 1997). However, not all studies show a clear spatial separation of these two processes. Descroix et al. (2007) for example found that saturation excess overland flow can also be important in semiarid climate, while infiltration excess overland flow also occurs in more humid climates. The simultaneous occurrence of infiltration excess and saturation excess overland flow was also observed in field experiments e.g. by Srinivasan et al. (2002). Preferential flow carrying significant amounts of pesticides to tile drains is closely linked to the occurrence of surface runoff, because preferential flow requires the lateral flow of water to the preferential flow paths (Flühler et al., 1996; Weiler and Naef, 2003). Furthermore, preferential flow paths may intercept surface runoff and direct it towards tile drains (Stamm et al., 2002). Preferential flow can also be fed by subsurface lateral flow and therefore occur without overland flow (e.g. Jarvis, 2007). However, the lateral flow towards the preferential flow paths requires high pesticide concentrations to result in significant pesticide transport. Therefore it needs to be initiated close to the surface where soil concentrations are high. We focus here on macropore flow that is fed by surface runoff. Therefore, the two runoff-generating mechanisms (infiltration excess and saturation excess) are also relevant for the input of pesticides into surface waters via preferential flow to tile drains. 
Even though the chemical properties of the pesticides may not affect the spatial pattern of losses, they are important in determining the pesticide mobilisation and transport behaviour. While the pesticide half life in soil determines the amount of pesticide that is present in soil at the time of rainfall (e.g. Louchart et al., 2001), the sorption behaviour can affect both mobilisation and transport. For many pesticides it has been shown that sorption equilibrium is only reached after weeks or months and therefore kinetic sorption has to be considered (see e.g. Vereecken et al., 2011, for a recent review of pesticide sorption studies). Several field studies have shown that sorption strength influences pesticide losses to streams and tile drains, leading to lower loss rates and lower peak concentrations for substances with stronger sorption (Brown and van Beinum, 2009; Gomides Freitas et al., 2008; Leu et al., 2004a; Louchart et al., 2001). Simulation models for catchment-scale pesticide transport usually assume equilibrium between sorbed and dissolved pesticide in soil. For example SWAT describes the mobilisation of pesticides into mobile water as follows:

$m_{\text {rel }}=\exp \left(\frac{-1}{\theta_{\text {sat }}+K_{\mathrm{d}} \times \rho} \times \frac{q_{\text {mobile }}}{z}\right)$

where $m_{\text {rel }}[-]$ is the amount of mobilised pesticide relative to the initial amount, $q_{\text {mobile }}[\mathrm{mm}]$ is the flux of mobile water per time-step, $\theta_{\text {sat }}[-]$ is the volumetric water content at saturation, $K_{\mathrm{d}}\left[1 \mathrm{~kg}^{-1}\right]$ is the distribution coefficient, $\rho\left[\mathrm{g} \mathrm{cm}^{-3}\right]$ is soil bulk density and $z[\mathrm{~mm}]$ is the depth of the soil layer (Neitsch et al., 2005).

For $A_{\text {connect }}$, the focus is on the connectivity of fast flow processes that are relevant for pesticide transport. In the analysis of overland flow connectivity, natural and anthropogenic depressions within a catchment are of major importance since they can retain large amounts of overland flow, which are prevented from reaching the stream (Barron et al., 2011; Frey et al., 2009; Kiesel et al., 2010). In addition to the depressions, man-made networks have a large influence on connectivity. Subsurface pipe networks (tile drains, road drainage etc.) can increase connectivity immensely. Areas outside the topographic catchment can also contribute as a result (Noll and Magee, 2009). Roads can act as barriers for overland flow or alternatively concentrate flow (Carluer and De Marsily, 2004; Payraudeau et al., 2009) and direct it to the stream via road drainage (e.g. Ledermann et al., 2010). Other small linear features such as tramlines and field edges may influence flow directions and therefore also connectivity substantially (e.g. Aurousseau et al., 2009; Heathwaite et al., 2005). Many of these spatial processes are subject to regional differences. They depend on climate and agricultural land management practices but also on general structural properties of agricultural catchments (field sizes, proportion of drained area, length and type of road network etc.).

A reliable spatial prediction of CSAs is necessary if site specific mitigation measures should be implemented in practice. However, a sound prediction requires a detailed understanding of the governing processes and their interactions. Such an understanding can be gained in field studies and field experiments at catchment scale, where the interplay of processes can be observed. There are only few comprehensive field data sets available for validating spatial predictions of herbicide losses within agricultural catchments (Gomides Freitas et al., 2008; Leu et al., 2004a,b). In these studies, the herbicide input into the catchments and the output through the stream were controlled and monitored. This setup does not allow investigation of individual processes occurring along the transport pathway from the field to the stream. Furthermore, only limited data on the catchment hydrology were collected, and all studies were carried out in the same region southeast of Zürich (Greifensee) in a small number of test catchments. The goal of this study was to improve the understanding of the process chain causing herbicide transport from the fields of application to streams, including:

1. Understanding the link between hydrological processes and herbicide mobilisation at catchment scale. Based on the knowledge from earlier studies (Gomides Freitas et al., 2008; Leu et al., 2004a,b), we expected that saturation excess overland flow would be the main mobilisation and transport process under the climatic conditions of the Swiss plateau. Accordingly, soil hydrology and connectivity were expected to be the drivers for herbicide transport.

2. Understanding the influence of the herbicide's chemical properties on mobilisation and transport. The expectations were that sorption plays an important role during the mobilisation of herbicides from soil to overland flow, while it should not affect transport once the substance is mobilised.

3. Understanding connectivity in a situation where a large part of the stream system is subsurface. We expected that only areas that are directly connected to the stream and drained areas can contribute to the herbicide load in the stream.

The understanding of the concentration dynamics in the stream requires the understanding of all three abovementioned topics and their interactions. The paper is structured as follows: In the results and discussion sections we first present the hydrologic results, then we show how chemical properties influenced mobilisation and transport of the herbicides and finally we report on the concentration dynamics in the stream.

\section{Materials and methods}

\subsection{Site description}

The study catchment is located in the northeast of Switzerland (see Fig. 1). The catchment area is $1.2 \mathrm{~km}^{2}$, topography 


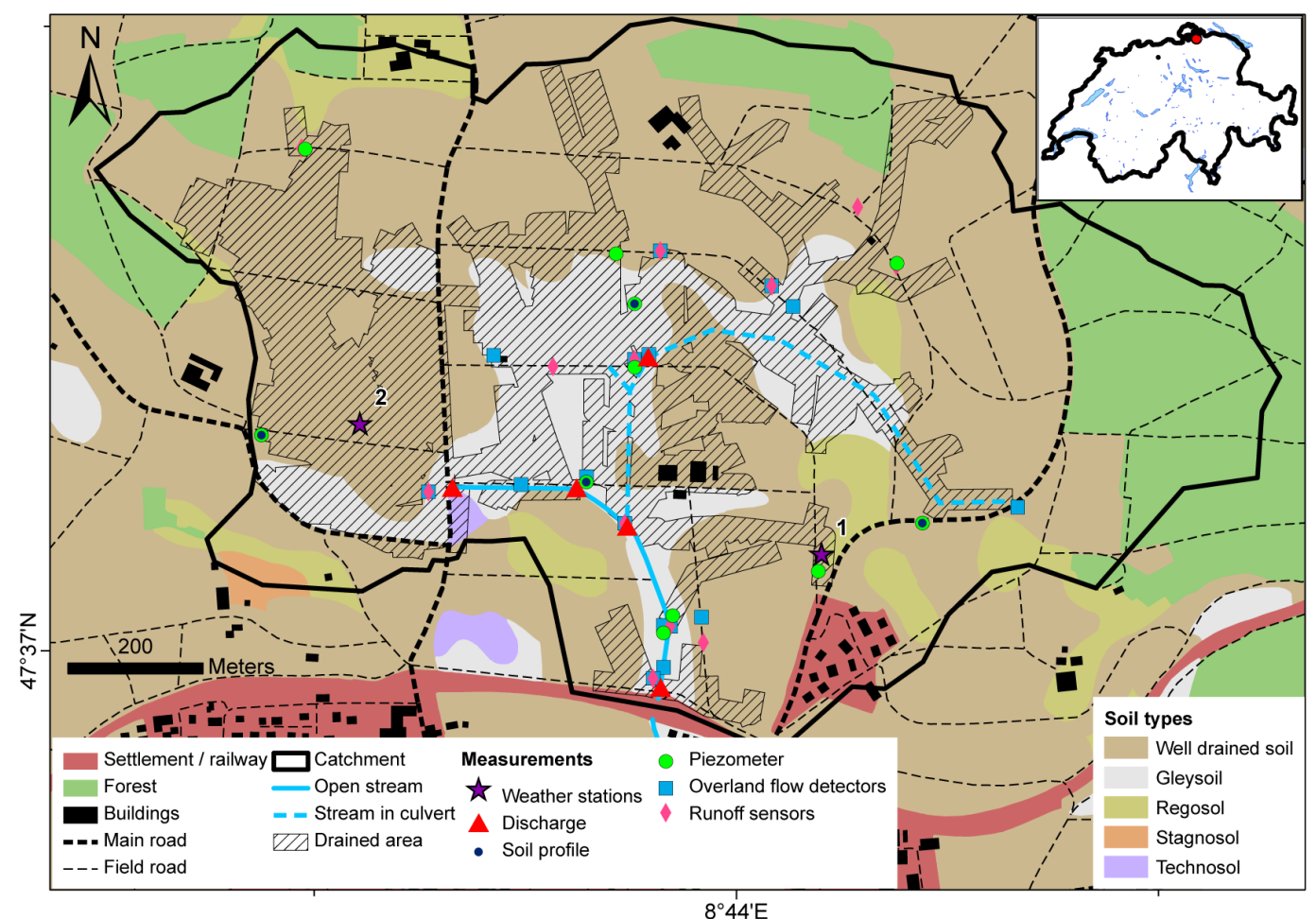

Fig. 1. The experimental catchment with soil types, land use and the hydrological measurement locations. Cambisols and luvisols were combined to the category of well drained soils. The small map in the top right corner depicts the location of the study site within Switzerland. Sources: FAL (1997); Swisstopo (2008); Gemeinde Ossingen (1995).

is moderate with altitudes ranging from 423 to $477 \mathrm{~m}$ a.s.l. and an average slope of $4.3^{\circ}\left(\min =0^{\circ}, \max =42^{\circ}\right.$, based on $2 \times 2 \mathrm{~m}$ digital elevation model (DEM), absolute accuracy: $\sigma=0.5 \mathrm{~m}$, resolution $=1 \mathrm{~cm}$, Swisstopo, 2003). The twenty-year mean annual precipitation at the closest permanent measurement station (Schaffhausen, $11 \mathrm{~km}$ north of the catchment) is $883 \mathrm{~mm}$ (Meteoschweiz, 2009). The soils developed on moraine material with a thickness of around ten metres, which is underlain with Süßwassermolasse (freshwater molasse) (Swisstopo, 2007). Soils in the centre of the catchment are poorly drained gleysoils. Well drained cambisols and eroded regosols are located in the higher parts of the catchment (FAL, 1997, see Fig. 1). Soil thickness (surface to $\mathrm{C}$ horizon) varies between $30 \mathrm{~cm}$ at the eroded locations and more than $2 \mathrm{~m}$ in the depressions and near the stream. The catchment is heavily modified by human activities; it encompasses a road network with a total length of $11.5 \mathrm{~km}$ (approximately $3 \mathrm{~km}$ are paved and drained, the rest is unpaved and not drained). The dominant land use is crop production ( $75 \%$ of the area), mainly corn, sugar beet, winter wheat and rape seed. Around $13 \%$ of the catchment is covered by forest, and a small settlement area is located in the southeast of the catchment. Three farms lie at least partly within the catchment (see Fig. 1). $47 \%$ of the agricultural land is drained by tile drains with a total length of over $21 \mathrm{~km}$ (Gemeinde Ossingen, 1995, the open stream has a length of
$550 \mathrm{~m}$ ). The stream system consists of two branches, an open ditch that was partly built as recipient for the drainage water and the main branch of the stream that runs in a culvert (see Fig. 1). The stream also receives the runoff from two main roads and from two farmyards (Gemeinde Ossingen, 2008). The paved area that drains into the catchment is approximately $15000 \mathrm{~m}^{2}$ (1.2\% of the area).

\subsection{Hydrological measurements}

Several hydrological variables were monitored in the catchment from summer 2008 to autumn 2009. Not all measurements cover the whole time period. However, during the experimental period from February 2009 to October 2009 all measurements depicted in Fig. 1 were running.

\subsubsection{Discharge and electrical conductivity of stream and drainage water}

We measured discharge at five locations in the catchment. At four sites $\left(O_{\mathrm{d}}, O_{\mathrm{u}}, S_{\mathrm{d}}, S_{\mathrm{u}}\right.$, see Fig. 2$)$, water level and flow velocity were measured using a Doppler probe and a pressure transducer (ISCO 750 area velocity flow module, Teledyne Inc., Los Angeles, CA, USA). Discharge was calculated using the exact cross section of these sites. At the fifth site $\left(O_{\mathrm{m}}\right.$, Fig. 2), discharge was determined by measuring the water level at a V-notch weir with a pressure transducer (Keller 


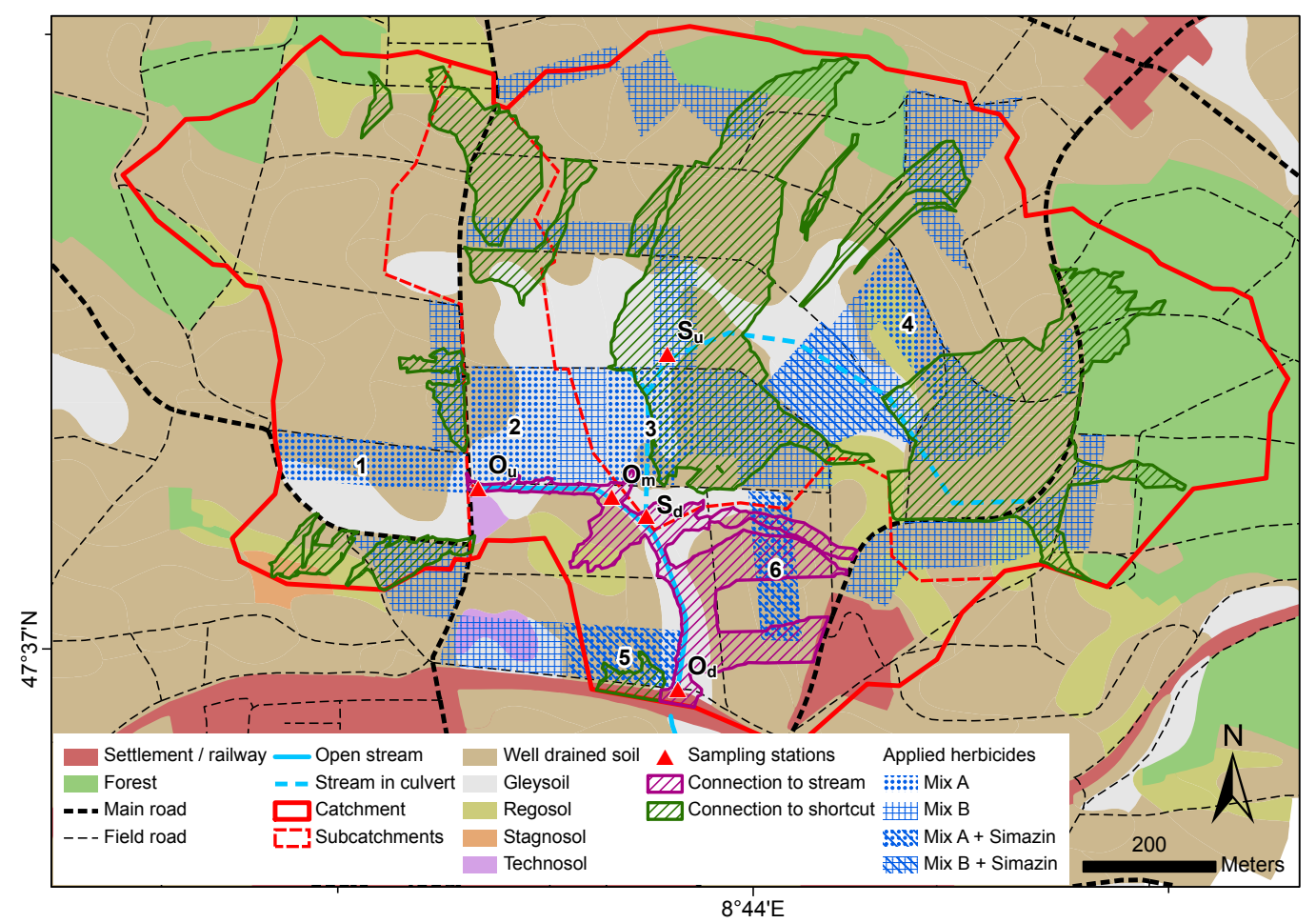

Fig. 2. Experimental setup with the six experimental fields (1 to 6, Mix A = atrazine, S-metolachlor and sulcotrione), the alternative fields (Mix B $=$ terbuthylazine and mesotrione) and the five sampling locations: $S_{\mathrm{u}}$ and $S_{\mathrm{d}}$ (subsurface upstream and downstream) and $O_{\mathrm{u}}, O_{\mathrm{m}}$ and $O_{\mathrm{d}}$ (open upstream, middle and downstream). The subcatchments of the sampling stations $O_{\mathrm{u}}$ and $S_{\mathrm{d}}$ are displayed. The area with a direct surface connection to the stream is shown together with the areas connected to manholes and storm drains (only connected areas $>1000 \mathrm{~m}^{2}$ are shown, see Sect. 3.1.2). Sources: Swisstopo (2008); FAL (1997).

PR-46X, KELLER AG für Druckmesstechnik, Winterthur, $\mathrm{CH})$ and using a rating curve of the form $Q=\alpha \times(h-\beta)^{\gamma}$, where $h$ is the water level and $\alpha, \beta$ and $\gamma$ are parameters (Herschy, 1995). The curve was fitted to 15 data points obtained by dilution experiments with $\mathrm{NaCl}$ (6 data points, CS547 Conductivity and Temperature Probe, Campbell Scientific, Inc., Loughborough, UK) and bucket measurements (9 data points). Discharge data from all stations were stored at $5 \mathrm{~min}$ intervals, either by the data logger of the sampler (ISCO 6700, ISCO 6712, Teledyne Inc., Los Angeles, CA, USA), or by an external data logger (CR10X, Campbell Scientific, Inc., Loughborough, UK). Runoff ratios were calculated for individual events by dividing the event discharge sum by the rain depth of the event. Figure 3 shows the time intervals used for the discharge sums.

At four discharge measurement stations $\left(O_{\mathrm{d}}, O_{\mathrm{m}}, O_{\mathrm{u}}, S_{\mathrm{d}}\right.$, Fig. 2), we also obtained electrical conductivity data at $5 \mathrm{~min}$ intervals (STS DL/N, STS Sensor Technik Sirnach AG, Sirnach, $\mathrm{CH}$, and CS547 Conductivity and Temperature Probe, Campbell Scientific, Inc., Loughborough, UK).

\subsubsection{Weather stations}

At weather station 1 (see Fig. 1) precipitation was measured at $15 \mathrm{~min}$ resolution with a tipping bucket rain gauge (R102, Campbell Scientific, Inc., Loughborough, UK). This rain gauge was out of order for 22 days (4 June 2009 to 25 June 2009). During this time, rain data from weather station 2 (see Fig. 1) were used (a mobile HP 100 Station run by Agroscope ART with a tipping bucket rain gauge: HP 100, Lufft GmbH, Fellbach, Germany). For two of the major rain events in the experimental period (events E2 and E9 in Table 1), rain data from both rain gauges are available.

\subsubsection{Piezometers}

We installed 11 piezometers to monitor groundwater levels at 15 min intervals (STS DL/N, STS Sensor Technik Sirnach AG, Sirnach, $\mathrm{CH}$, and Keller DCX-22, KELLER AG für Druckmesstechnik, Winterthur, $\mathrm{CH}$ ). The installation depth varied between 1.5 and $2.7 \mathrm{~m}$ below the surface.

\subsubsection{Soil moisture}

TDR probes and tensiometers were installed in four soil profiles to measure soil water content and suction pressure at 
Table 1. Characteristics of the 13 rain events with the number of locations where overland flow (OF) was observed (results from runoff sensors and overland flow detectors), the number of overland flow samples, the average electrical conductivity (EC) in the overland flow samples and the number of piezometers that had maximum water levels (WL) less than $30 \mathrm{~cm}$ below the surface during the event.

\begin{tabular}{lccccccc}
\hline Event & $\begin{array}{c}\text { Rain } \\
\text { depth } \\
\text { mm }\end{array}$ & $\begin{array}{c}\text { Max rain } \\
\text { intensity } \\
\text { mm }(15 \text { min })\end{array}$ & $\begin{array}{c}\text { Runoff } \\
\text { ratio } \\
\%\end{array}$ & $\begin{array}{c}\text { Locations } \\
\text { with OF } \\
\text { (out of } 21)\end{array}$ & $\begin{array}{c}\text { Samples } \\
\text { OF }\end{array}$ & $\begin{array}{c}\text { Mean EC } \\
\mu \mathrm{S} \mathrm{cm}^{-1}\end{array}$ & $\begin{array}{c}\text { Piezometers } \\
\text { with WL }<0.3 \mathrm{~m}\end{array}$ \\
\hline E1 & 9.8 & 4.2 & 6 & 1 & 0 & - & $0 / 10$ \\
E2 & 45.6 & 12.0 & 11 & 8 & 7 & $565^{*}$ & $2 / 10$ \\
E3 & 22.2 & 4.2 & 10 & 9 & 6 & 187 & $1 / 10$ \\
E4 & 7.8 & 1.3 & 13 & 1 & 0 & - & $0 / 10$ \\
E5 & 5.6 & 1.0 & 8 & 2 & 0 & - & $0 / 10$ \\
E6 & 9.6 & 0.8 & 9 & 4 & 0 & - & $0 / 10$ \\
E7 & 18.2 & 1.6 & 9 & 7 & 3 & 183 & $0 / 10$ \\
E8 & 14.6 & 1.4 & 12 & 7 & 4 & 206 & $0 / 10$ \\
E9 & 36.8 & 9.4 & 12 & 11 & 8 & 209 & $3 / 10$ \\
E10 & 6.4 & 0.6 & 4 & 5 & 0 & - & $0 / 9$ \\
E11 & 15.2 & 3.6 & 7 & 8 & 3 & 192 & $0 / 9$ \\
E12 & 51.6 & 8.8 & 12 & 15 & 12 & 167 & $4 / 9$ \\
E13 & 57 & 3.4 & 41 & 17 & 14 & 409 & $7 / 9$ \\
\hline
\end{tabular}

${ }^{*}$ Fertilizer applied at the day of the event.

four depths between 0.1 and $1.1 \mathrm{~m}$ below the surface. The exact depths at the different locations were selected according to the soil horizons. Two TDR probes (TDR100, Campbell Scientific, Inc., Loughborough, UK, and two rod probes) and three tensiometers (ceramic cups: High Flow Porous Ceramic Cup $653 \times 1$ B1M3 1 bar, Soil Moisture Equipment, Goleta, CA, USA; pressure transducers: 26 PCCFA3D, Honeywell, Minneapolis, MN, USA) were installed at each depth. All soil profile data were stored at hourly intervals in a data logger (CR10X, Campbell Scientific, Inc., Loughborough, UK).

\subsubsection{Overland flow and erosion}

Two different devices were used to detect overland flow:

1. The runoff sensor is an electronic device based on the idea by Srinivasan et al. (2000). It detects overland flow by electric contacts on a small $\mathrm{V}$-notch weir and stores the data in a data logger. This system delivers timeresolved occurrence of overland flow.

2. The overland flow detector is a simple collection bottle similar to the device described by Kirkby et al. (1976). If it collects water during a rain event, this indicates that overland flow occurred.

A total of twelve runoff sensors and 16 overland flow detectors were installed at 21 locations (seven locations were equipped with both instruments, see Fig. 1). During and after some of the events, signs of overland flow (E2, E9, E13), ponding (E2, E9, E12, E13) and erosion (E2, E9, E12, E13) were mapped (see Fig. 4). The mapping was carried out on an ad-hoc basis by different people and without systematic coverage of the entire catchment. Nevertheless, it complements the information on the spatial extent of overland flow and erosion from the point measurements of the runoff sensors and overland flow detectors, and therefore adds important spatial information.

In addition to registering the locations of overland flow, we also analysed the chemical composition of overland flow samples. We used the samples taken by the overland flow detectors and additionally collected grab samples of overland flow at several locations during events E2 and E9. We measured herbicide concentrations in these samples (see Sect. 2.5). In the samples from the overland flow detectors, we also determined electrical conductivity (STS DL/N, STS Sensor Technik Sirnach AG, Sirnach, CH).

\subsection{Herbicide application}

On 19 May 2009 we performed a controlled herbicide application on corn fields in the catchment. The fields were divided into two groups. Six of the corn fields were selected as experimental fields (labelled 1 to 6 in Fig. 2), where we had full control over the application. All experimental fields were sprayed on the same day with the same spraying device. The rest of the corn fields in the catchment (alternative fields) received a different herbicide mixture. Not all of the alternative fields could be sprayed on the same day with the same spraying device. The herbicides atrazine (CAS no.: 1912-24-9), S-metolachlor (87392-12-9), sulcotrione (99105-77-8) and simazine (122-34-9) (see Table 2) were applied on the six experimental fields in two different mixtures. The experimental fields 1 to 4 received Mix A (atrazine $800 \mathrm{~g} \mathrm{ha}^{-1}$, S-metolachlor $960 \mathrm{~g} \mathrm{ha}^{-1}$ and sulcotrione $450 \mathrm{~g} \mathrm{ha}^{-1}$ ) while fields 5 and 6 were sprayed 


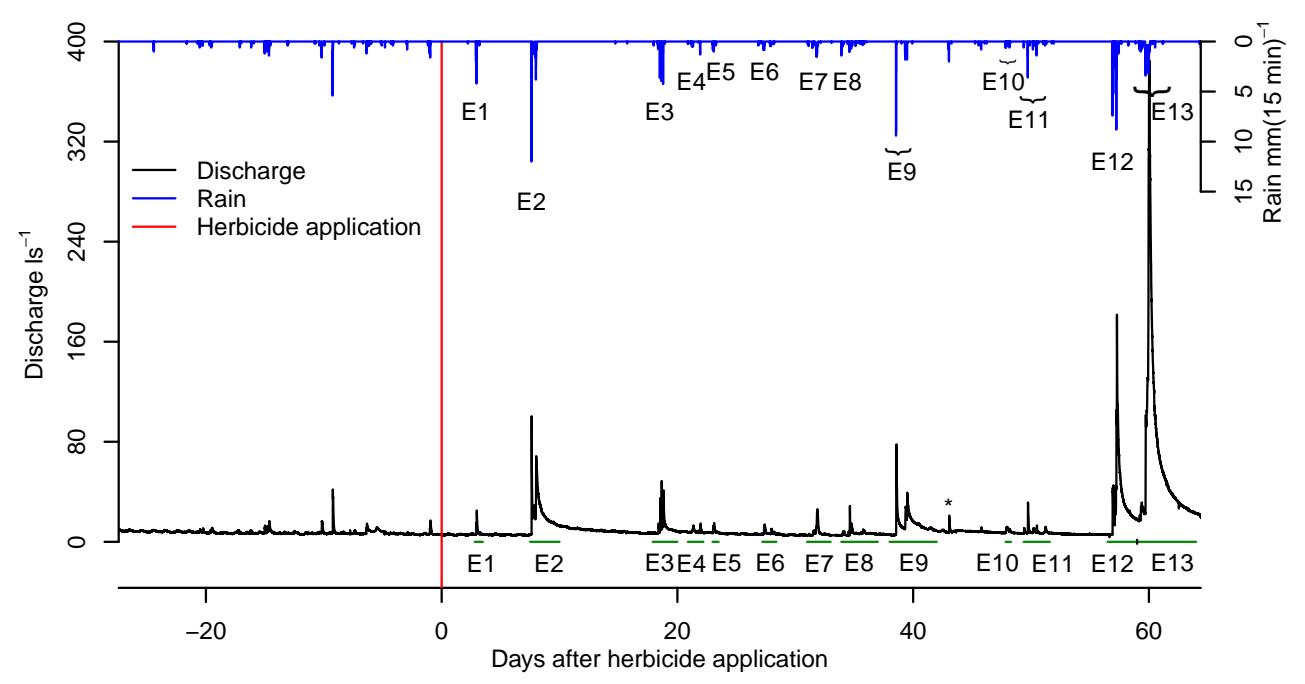

Fig. 3. Rainfall and discharge at the outlet of the catchment (station $O_{\mathrm{d}}$ ) prior to and after the controlled herbicide application (19 May 2009). The event numbers refer to the events described in Table 1 . The green lines indicate the duration of discharge used for runoff ratio calculation. $*$ : event with $<5 \mathrm{~mm}$ rain.

with Mix A and simazine (200 $\mathrm{g} \mathrm{ha}^{-1}$, see Fig. 2). The alternative fields were sprayed with a mixture of terbuthylazine (5915-41-3, $495 \mathrm{~g} \mathrm{ha}^{-1}$ ) and mesotrione (104206-82$8,105 \mathrm{~g} \mathrm{ha}^{-1}$ ) (Mix B in Fig. 2). None of these substances was used elsewhere in the catchment. Moreover, we recorded the substance amounts and application dates of all the alternative fields.

To ensure the correct dose and concentration in the spray solution, the experimental herbicides were weighed exactly before being mixed in the spraying tank. Samples from each tank filling were taken and analysed. The exact amount of spray solution applied on each field was determined by a flow meter mounted on the spraying equipment. A calibrated scale bar on the spraying tank was also used to estimate the applied volume per field in addition to the flow meter. The extent of the sprayed area was marked with wooden sticks; their exact location was determined by a differential GPS (Leica GPS1200, Leica Geosystems AG, Heerbrugg, Switzerland). Owing to these control measures, the exact areas and applied rates are known for each field and each substance.

\subsection{Water sampling}

Water samples from stream and tile drains were taken at the five discharge measurement stations prior to the herbicide application and during two months after application. These five locations were sampled at high temporal resolution during the 13 rain events that occurred during the experimental period. The sampling strategy was as in Wittmer et al. (2010). Time-proportional samples were taken by automatic water samplers equipped with 24 polypropylene bottles (ISCO 2900, 6700, 6712, Teledyne Inc., Los Angeles, CA, USA). The samplers were triggered when a predefined water level was exceeded. During the first six hours of an event, time-proportional 15-min composite samples (three aliquots every $5 \mathrm{~min}$ ) were taken. Afterwards, the sampling frequency was reduced to one composite sample per hour (four aliquots every $15 \mathrm{~min}$ ). This sampling strategy yielded enough samples for short events, and lasted long enough (max. $30 \mathrm{~h}$ ) to restart the samplers during large events. Grab samples were taken during base flow periods.

To keep the number of samples in a feasible range for subsequent analysis in the lab, the samples were selected in a two-step procedure. First, they were pre-selected in the field to cover the entire hydrograph of the event. A total of 1500 samples was brought to the lab in $250 \mathrm{ml}$ glass bottles and stored at $4{ }^{\circ} \mathrm{C}$. Every other sample was additionally stored at $-20^{\circ} \mathrm{C}(150 \mathrm{ml}$ in a $250 \mathrm{ml}$ glass bottle). Out of the total of 1500 samples, six hundred were selected for analysis in a step-by-step procedure. First, the seven events with the highest rain amounts were selected for analysis (events E1, E2, E3, E7, E9, E12, E13 in Table 1, see also Fig. 3) and a few samples per event were analysed (beginning, peak, recession). Finally, we selected further samples to adequately represent the dynamics of the chemograph.

\subsection{Analysis of water samples}

Sorption of the analytes to the bottles in the automatic water samplers was investigated previously and sorption was found to be negligible. Stability of the analytes was investigated over a period of four months at $4{ }^{\circ} \mathrm{C}$. No degradation was observed during the first two months of storage. However, sulcotrione and mesotrione showed slight degradation after two months in unfiltered samples; therefore, data for these two analytes are only reported from samples stored at $-20^{\circ} \mathrm{C}$ after this time (two months). 
Table 2. The molecular structures of the applied substances with their sorption coefficient to organic carbon $\left(K_{\mathrm{Oc}}\right)$ and their half life in field soil $\left(\mathrm{DT}_{50}\right)$. All data taken from PPDB (2010).

(d)

Analysis of the herbicides was performed according to Singer et al. (2010). The samples were filtered through glassfibre filters (GF/F, $0.7 \mu \mathrm{m}$, Whatman) and isotope-labelled internal standards for all compounds were spiked to $50 \mathrm{ml}$ of filtered sample. The samples were analysed by online solid-phase extraction (SPE) coupled to liquid chromatography followed by a triple quadrupole mass spectrometer (LC-MS/MS). Sample enrichment was achieved on a Strata$\mathrm{X}$ extraction cartridge $(20 \times 2.1 \mathrm{~mm}$ I.D. $33 \mu \mathrm{m}$ particle size, Phenomenex, Brechbühler AG, Schlieren, Switzerland). LC separation was performed on a XBridge C18 column (50 $\mathrm{mm} \times 2$, Waters, Baden-Dättwil, Switzerland), and detection by a TSQ Quantum triple quadrupole MS (Thermo, San Jose, CA, USA). The limit of detection (LOD) was in the range of 2 to $10 \mathrm{ng} \mathrm{l}^{-1}$ for all compounds. Quality control consisted of aliquots of spiked and un-spiked environmental samples analysed with each analytical run. The resulting inter-day precision of the method was 5 to $12 \%$ for the six compounds. The average accuracy for each analyte was between 101 and $105 \%$.

\subsection{Soil sampling and sample preparation}

From each of the six experimental fields (see Fig. 2), we took topsoil samples at seven dates: before herbicide application, directly after application and on days 3, 7, 15, 30 and 60 after application. Every one of these soil samples consisted of 20 subsamples taken randomly across the field. The 20 subsamples were mixed and combined to one topsoil sample to represent the whole field. A stainless steel probe with $5.4 \mathrm{~cm}$ diameter was used for soil sampling, the samples were taken from 0 to $5 \mathrm{~cm}$ depth. The samples were stored in a polypropylene box tightly sealed with a lid.
After sampling, all soil samples were stored at $-20^{\circ} \mathrm{C}$. Prior to analysis, all soil samples were crushed with a hammer mill and kept frozen by adding dry ice. After milling, the soils were left outside for twelve hours with open lids to eliminate the $\mathrm{CO}_{2}$ added during milling. The soil samples were then stored at $-20^{\circ} \mathrm{C}$ until further analysis.

\subsection{Soil extraction and analytics}

Herbicide concentrations were measured in all soil samples using two different extraction methods. For the total soil concentration we used pressurized liquid extraction (PLE). The concentration in the centrifugation solution (see below) was used as a proxy for the porewater concentration.

\subsubsection{Total soil concentration}

The herbicides were extracted by PLE using an ASE 350 Accelerated Solvent Extractor (Dionex, Sunnyvale, CA, USA). Extraction took place with a solvent mixture of acetone: $1 \%$ phosphoric acid, 70:30 (volume ratio) at $100^{\circ} \mathrm{C}$. The PLE extract was stored at $-20^{\circ} \mathrm{C}$. The clean-up of the PLE extract was done in four main steps after addition of an internal standard solution. (1) The acetone was removed by rotary evaporation at $35^{\circ} \mathrm{C}$. (2) HPLC grade water, $3.9 \mathrm{~g}$ of acetonitrile, $1.6 \mathrm{~g}$ of anhydrous magnesium sulfate and $0.3 \mathrm{~g}$ of ammonium chloride were added to the remaining extract for the liquid-liquid extraction. The tube was shaken for about $2 \mathrm{~min}$ and centrifuged for $4 \mathrm{~min}$ at $500 \times \mathrm{g}$ (Ultrafuge Filtron, Heraeus) to separate the acetonitrile phase. (3) The acetonitrile phase was reduced to a volume of $500 \mu$ l under a nitrogen stream; $500 \mu$ l of methanol were then added. (4) The solution was filtered with a syringe through a $0.2 \mu \mathrm{m}$ PTFE filter and stored at $4{ }^{\circ} \mathrm{C}$ until quantification. 


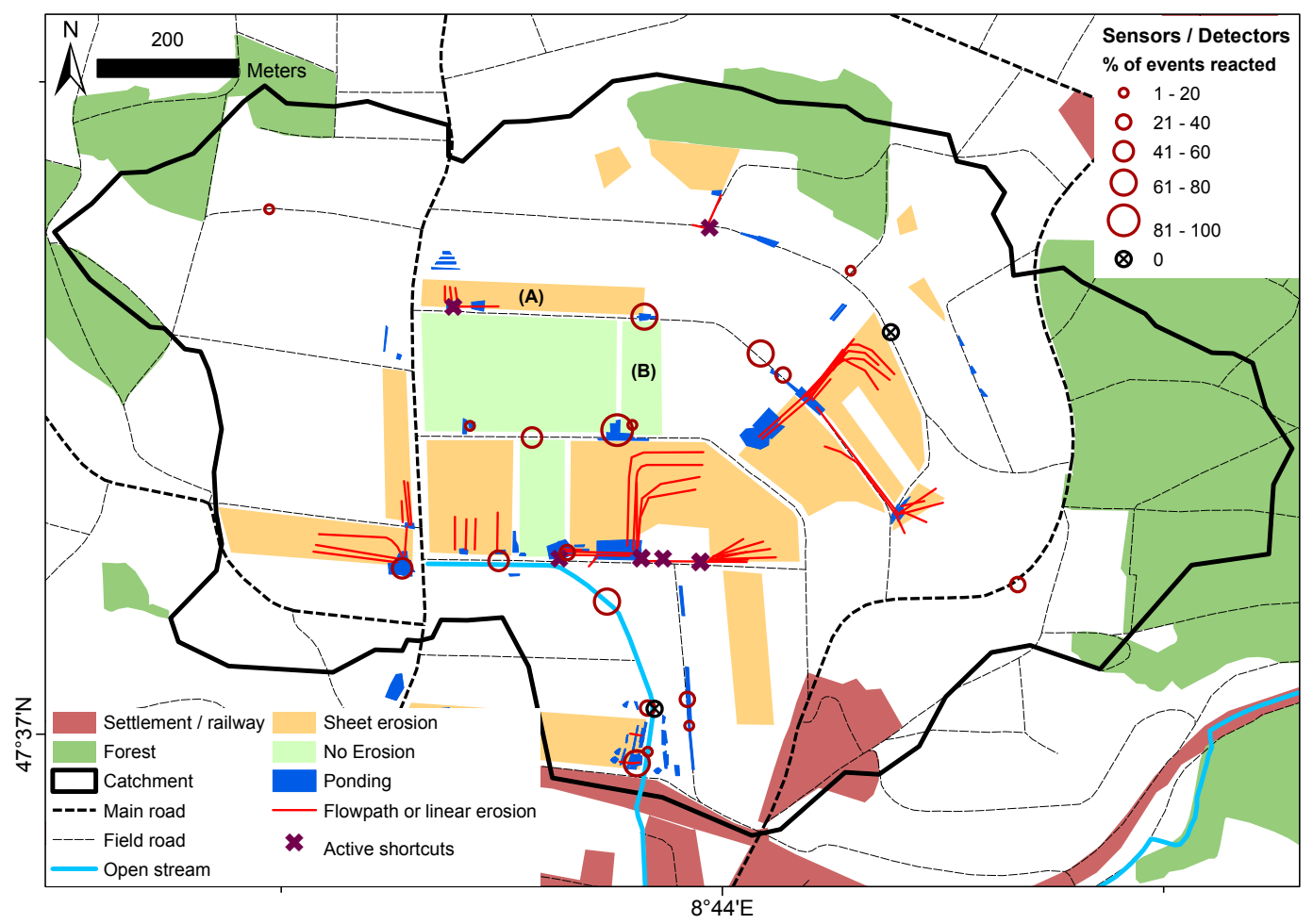

Fig. 4. Erosion mapping (sheet and linear erosion) for four events (E2, E9, E12, E13), direct observation of overland flow paths (E2, E9, E13) and ponding (E2, E9, E12, E13) and results from runoff sensors and overland flow detectors showing the percentage of events in which overland flow occurred. (A) and (B) are two corn fields discussed in Sect. 3.1.1. White areas were either unobserved, or no erosion or overland flow were observed (see text). Fields marked "No Erosion" were surveyed but did not show signs of erosion. Source: Swisstopo (2008).

\subsubsection{Pore water}

In order to extract pore water from dry soil samples $(<80 \%$ of the water holding capacity, WHC), the water content of these samples was adjusted to $80 \%$ of the WHC by adding the appropriate volume of water. The WHC is the amount of water a soil can retain against gravity. The WHC was determined for two soil samples per field as follows. Approximately $2 \mathrm{~cm}$ of glass wool were packed into the bottom of a glass tube containing a porous glass frit at the bottom, followed by a weighed amount of wet soil. The soil was then saturated from the bottom by placing the glass tube in a beaker filled with water for $24 \mathrm{~h}$. The glass tubes were then taken out of the beaker and placed on a dry surface to drain for $4 \mathrm{~h}$; they were covered with a beaker to prevent evaporation. The water content at the end of the $4 \mathrm{~h}$ was used as WHC, and the average value of the two soils from each field was used for all samples from the respective field. To obtain the pore water sample, a weighed amount of approximately $3 \mathrm{~g}$ of thawed soil sample (with the added water if necessary, see above) was placed into a centrifuge filter tube with a $0.45 \mu \mathrm{m}$ PTFE membrane (Ultrafree-CL, Millipore). The centrifuge tubes were then stored at $4{ }^{\circ} \mathrm{C}$ for roughly $24 \mathrm{~h}$ to obtain an apparent equilibrium between the pore water and the solid phase. The samples were centrifuged for $20 \mathrm{~min}$ at
$2000 \times$ g. After centrifugation, the internal standard mixture was added to the collected pore water and the solution was stored at $4{ }^{\circ} \mathrm{C}$ until quantification.

\subsubsection{Quantification}

Analysis of the extracts was done with liquid chromatography coupled to a triple quadrupole mass spectrometer (LCMS/MS). Compounds were separated by reversed-phase LC using a Synergi C18 polar RP column $(100 \times 3 \mathrm{~mm} \mathrm{ID \text {, }}$ $2.5 \mu \mathrm{m}$ particle size, equipped with an inline-filter, Phenomenex, Torrance, CA, USA) and detected by a TSQ Quantum triple quadrupole MS (Thermo, San Jose, CA, USA).

\subsubsection{Half life calculation}

We calculated the herbicides' half lives in soil based on the total soil concentrations (corresponding to the concentration measured with PLE) with first-order kinetics. Dissipation of sulcotrione on all fields and of atrazine and S-metolachlor on some fields slowed down after day 30 . For these cases only concentration data until day 30 were used for the calculation of the half lives, while for the other cases all data points (until day 60) were used. 


\subsubsection{Distribution coefficients}

The distribution of the herbicides between the dissolved and the sorbed phase was expressed by the apparent distribution coefficient $K_{\mathrm{d}}\left[1 \mathrm{~kg}^{-1}\right]$ in all soil samples:

$K_{\mathrm{d}}=\frac{C_{\text {sorbed }}}{C_{\text {porewater }}}=\frac{C_{\text {PLE }}-C_{\text {PWfraction }}}{C_{\text {porewater }}}$

$C_{\text {PLE }}\left[\mathrm{ng} \mathrm{kg}^{-1}\right]$ is the concentration obtained by PLE expressed per mass of dry soil, $C_{\mathrm{PWfraction}}\left[\mathrm{ng} \mathrm{kg}^{-1}\right]$ is the pore water concentration expressed per mass of dry soil, and $C_{\text {porewater }}\left[\mathrm{ng} \mathrm{l}^{-1}\right]$ is the measured pore water concentration in the water phase. A more detailed description of soil extraction and analysis is given in Camenzuli (2010).

\subsection{Mobilisation coefficient}

A mobilisation coefficient $M$ was used to compare the mobilisation of different herbicides from soil to overland flow. The coefficient $M$ is defined as the ratio of overland flow concentration to total soil concentration (PLE concentration). We only used overland flow samples where the origin of the water could be attributed to one single experimental field.

\subsection{Retention coefficient}

We define a retention coefficient $R$ to describe the effect of sorption on herbicide transport from ponding overland flow to tile drains. $R$ is the ratio of overland flow concentration on a given field to the concentration in the tile drain of that field at the corresponding time. For event E2 (Fig. 3), we calculated retention coefficients for all the experimental substances on experimental field 1 (Fig. 2). Two samples of ponding overland flow on field 1 were available, one at the beginning of the event and one at the end. These samples were used for calculating $R$ together with the two samples from station $O_{\mathrm{u}}$ that were taken briefly after sampling the overland flow.

\subsection{GIS analysis}

\subsubsection{Catchment delineation}

The catchment boundary was calculated in ArcGIS (ESRI, ArcGIS Desktop, 9.3.1) based on the $2 \times 2 \mathrm{~m}$ DEM (Swisstopo, 2003) and manually adapted after field observations. The topographical catchment does not coincide completely with the subsurface catchment. In some areas that belong to the topographical catchment, the tile drains divert the water outside of the catchment. These areas were excluded. In contrast, the settlement area in the southeast was kept in the catchment, even though the water from sealed areas in the settlement leaves the catchment. The subcatchments of the discharge and sampling stations were delineated based on topography and the detailed tile drain map (Swisstopo, 2003; Gemeinde Ossingen, 1995). Subcatchments calculated from surface topography were not always congruent with the tile drain subcatchments. Priority was given to the tile drain catchments.

\subsubsection{Drained area}

The drained area shown in Fig. 1 was calculated as a buffer of $15 \mathrm{~m}$ around the drainage pipes. This area does not correspond to the actual catchment of the drainage pipes, but was used to calculate the drained area percentage of the whole catchment and to visualize the drained area.

\subsubsection{Connectivity analysis}

The original $2 \times 2 \mathrm{~m}$ DEM (Swisstopo, 2003) was used for the analysis of surface connectivity. Firstly, very small or shallow depressions were removed, as these can either be artifacts in the DEM or too shallow to trap significant amounts of overland flow. Depressions consisting of one or two cells and those with a maximum depth of less than $5 \mathrm{~cm}$ were filled. Secondly, the cells in the open stream were incised to the depth of the average water level. Depression analysis and filling as well as stream incision were performed in TAS (TAS geographical information system version 2.0.9, John Lindsey 2005). Based on this corrected DEM, flow directions and flow accumulation were calculated in ArcGIS (ESRI, ArcGIS Desktop, 9.3.1). The lowest stream channel cell was used as pour point for the catchment calculation to determine the area connected directly to the stream on the surface. For the determination of areas connected to manholes of the drainage system or to storm drains for road and farmyard runoff, the locations of these features were used as pour points for the catchment calculation (Gemeinde Ossingen, 1995, 2008). One farmyard storm drain was manually shifted to a cell with higher flow accumulation, because the flow accumulation raster was affected by the farm buildings in this area.

\section{Results}

\subsection{Rainfall and hydrological processes}

The period before the herbicide application was rather dry, with $66 \mathrm{~mm}$ of rain in the 50 days before application. There was no significant discharge event in this period (Fig. 3). Afterwards, the weather conditions changed: From 19 May 2009 to 21 July 2009, thirteen rain events of more than $5 \mathrm{~mm}$ were recorded. Five of them had more than $20 \mathrm{~mm}$ of rain, and a total of $333 \mathrm{~mm}$ rainfall was measured in this period (see Fig. 3 and Table 1). Four of the five largest events (E2, $\mathrm{E} 3, \mathrm{E} 9, \mathrm{E} 12, \mathrm{E} 13)$ were thunderstorms with rather high rain intensities and short duration; only event E13 was a longer lasting, low intensity rain event (see Fig. 3 and Table 1). Runoff ratios were between 4 and $13 \%$ for events E1 to E12. Event E13 had a runoff ratio of more than $40 \%$, indicating 
that this event had a different runoff regime than the other events in the experimental period.

Human modification has a strong influence on the catchment hydrology. The largest part of the stream network is subsurface and tile drains provided most of the discharge. Even though the catchment has a large storage capacity due to the artificial drainage and therefore reacts slowly (low runoff ratios in most of the events, see Table 1), the hydrograph at some of the measurement stations showed very pronounced discharge peaks, because road and farmyard runoff is directly connected to the drainage system and the stream (see Figs. 5 and 6).

\subsubsection{Overland flow and erosion}

During the experimental period, we frequently observed overland flow and erosion on different fields distributed over the whole catchment (see Fig. 4 and Table 1). Overland flow was observed at least at one location in all of the rain events (Table 1).

Piezometer data showed that the groundwater level was often low before and during rain events. During events E2, E3 and E9 it rose to a level of less than $30 \mathrm{~cm}$ below the surface in two, one and three piezometers, respectively. Four piezometers reached this level during event E12. However, during event E13, the groundwater level rose close to the surface in seven out of nine piezometers (Table 1). We did not observe perched water tables in any of the four soil profiles. Rising groundwater levels were therefore not limited to locations with low conductivity layers in the soil profile.

Table 1 shows the mean electrical conductivities (EC) in the overland flow samples from eight events. Except for events $\mathrm{E} 2$ and $\mathrm{E} 13\left(\mathrm{EC}>400 \mu \mathrm{S} \mathrm{cm}^{-1}\right.$ ), all the values were around $200 \mu \mathrm{S} \mathrm{cm}^{-1}$.

Figure 4 gives a spatial overview of the field observations of overland flow and erosion. Neither of these processes was limited to locations with high groundwater levels, but they were distributed across the whole catchment area. However, erosion was only observed on corn fields during the study period, not on wheat fields with high soil coverage. In addition, the land management on the corn fields played an important role for the risk of overland flow. The type of ploughing and harrowing as well as the addition of organic material in the past years seemed to be important factors affecting the infiltration capacity of a field. This can be illustrated with fields (A) and (B) in Fig. 4. Both were corn fields with comparable soil coverage and similar soil texture and topography. Erosion and overland flow were frequently observed on field (A), but rarely on field (B). The differences can be explained with the land management: field (A) was harrowed very finely, leading to very small and crushed soil aggregates at the surface, low surface roughness and small detention storage. On the contrary, field (B) was harrowed only roughly, leading to a more irregular soil surface with intact

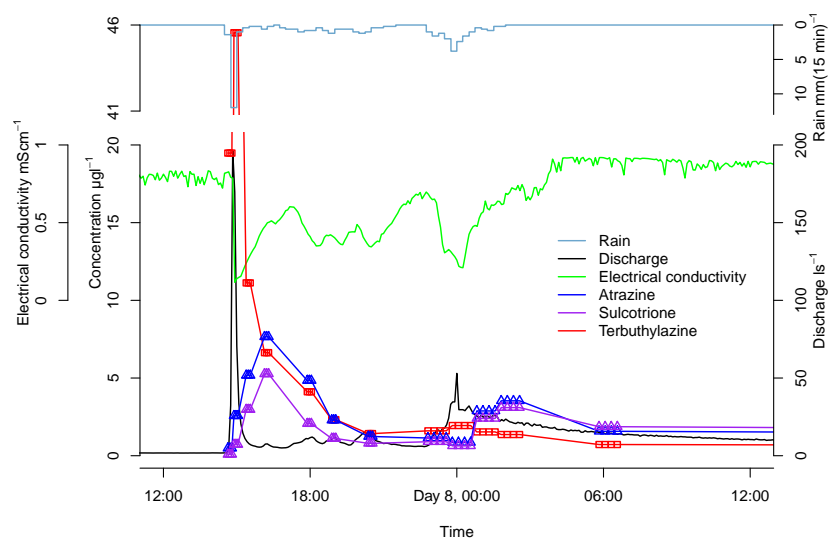

Fig. 5. Concentration dynamics of three substances at station $S_{\mathrm{d}}$ together with rain intensity, discharge, and electrical conductivity in the stream during event E2 (26 June 2009, seven days after application). The symbols represent the sampling time of the individual sample aliquots (see Sect. 2.4).

soil aggregates, a high surface roughness and larger detention storage. Additionally solid manure was applied on field (B) before ploughing.

\subsubsection{Connectivity}

Based on the connectivity analysis (Sect. 2.10.3), only $4.4 \%$ of the catchment area is directly connected to the stream on the surface (see Fig. 2), due to depressions within the catchment or topographic barriers (e.g. field roads) preventing the overland flow from flowing to the stream directly (see Fig. 4, which shows that ponding was often observed beside roads). However, the extended pipe network in the underground (tile drains as well as road and farmyard drainage), which is directly connected to the stream, offered two additional fast transport pathways for herbicides in overland flow: (i) direct shortcuts via maintenance manholes of the drainage system or storm drains for road and farmyard runoff (this pathway will be called shortcut in the following) and (ii) ponding of overland flow in depressions and macropore flow to the drainage system. Figure 7 shows examples of these two pathways observed during event E2. The connectivity analysis revealed that the area connected to shortcuts is much larger ( $23 \%$ of the catchment area) than the area connected to the stream directly (Fig. 2). Several shortcuts were observed to be active during the experiment. Figure 4 shows all shortcuts that were observed (in the field) to be active at least once, Fig. 7 shows a picture of an active shortcut.

\subsection{Influence of compound properties}

\subsubsection{Herbicide dissipation and sorption}

Average half lives on the six experimental fields were 9.5, 13.8 and 5.5 days for atrazine, S-metolachlor and sulcotrione, 


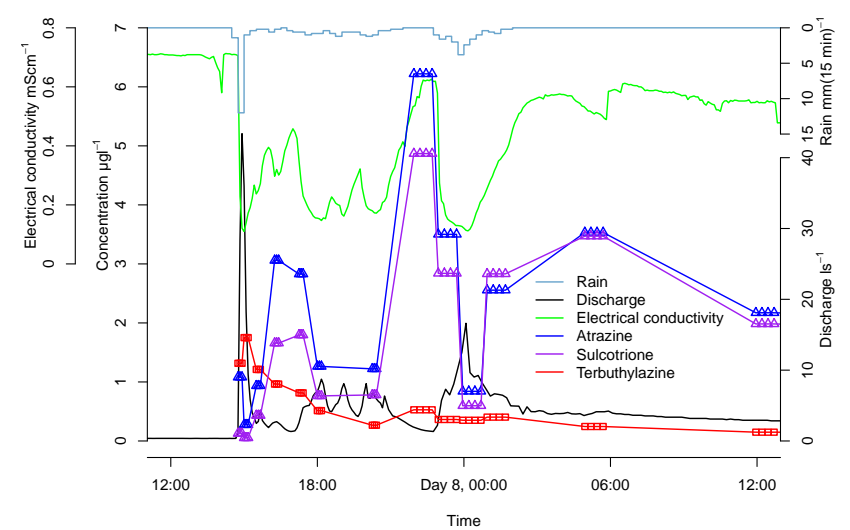

Fig. 6. Concentration dynamics of three substances at station $O_{\mathrm{u}}$ together with rain intensity, discharge, and electrical conductivity in the stream during event E2 (26 June 2009, seven days after application). The symbols represent the sampling time of the individual sample aliquots (see Sect. 2.4).

respectively (Camenzuli, 2010). These values are well within the range reported in literature (see Table 2).

Sorption of the herbicides to soil was assessed by the apparent distribution coefficient $K_{\mathrm{d}}$ between the sorbed and the dissolved fraction (Eq. 3). Sorption was strongest for $\mathrm{S}$-metolachlor, followed by atrazine and sulcotrione on all the experimental fields. On the application day, the $K_{\mathrm{d}}$ values on the experimental fields were in the range of 0.7 to $1.51 \mathrm{~kg}^{-1}, 1.4$ to $2.61 \mathrm{~kg}^{-1}$, and 0.1 to $0.21 \mathrm{~kg}^{-1}$ for atrazine, S-metolachlor and sulcotrione, respectively. The apparent distribution coefficient $K_{\mathrm{d}}$ of all substances increased with time. The magnitude of this kinetic sorption effect was largest for sulcotrione (3.2- to 14-fold increase from day 0 to day 30 ), followed by atrazine (1.3- to 10 -fold increase) and S-metolachlor (1.3- to 2.5-fold increase). As it can be seen from the large ranges of $K_{\mathrm{d}}$ increase, the variance between the different fields was large (Camenzuli, 2010). The magnitude of the kinetic sorption effect and its variability are comparable to the observations reported by Gomides Freitas et al. (2008).

\subsubsection{Overland flow concentration and herbicide mobilisation}

Herbicide concentrations in the overland flow samples varied heavily in space and time. The concentrations at each overland flow sampling site decreased with time. The concentrations in overland flow samples measured during event E2 differed by three orders of magnitude depending on the sampling location (atrazine: 0.58 to $426.3 \mu \mathrm{g} \mathrm{l}^{-1}$, Smetolachlor: 0.42 to $466.8 \mu \mathrm{g} \mathrm{l^{-1 }}$, sulcotrione: $<0.125$ to $97.9 \mu \mathrm{g}^{-1}$ ).

The mobilisation coefficient $M$ was used to investigate the influence of sorption on the mobilisation of the herbicides. We calculated $M$ ratios for all substance pairs
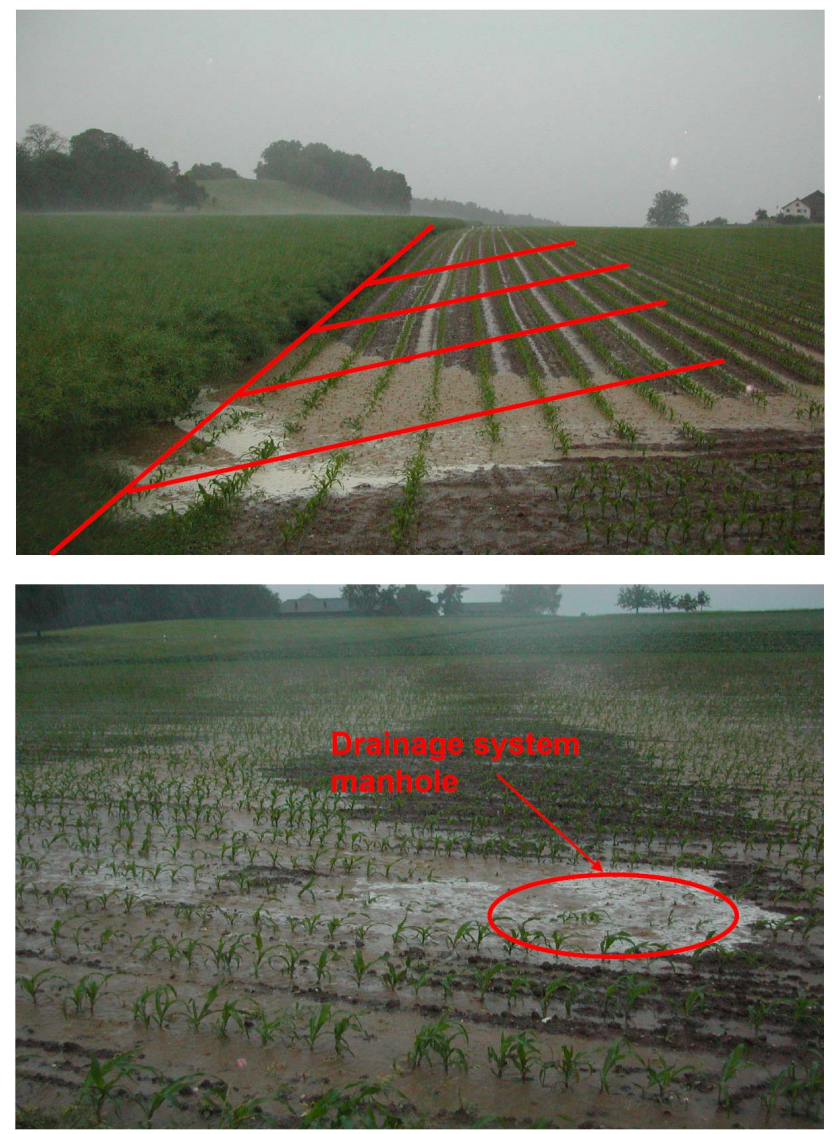

Fig. 7. Example pictures from event E2. Ponding overland flow in a drained depression on experimental field 1 (top) and overland flow entering a shortcut (bottom).

( $\left.M_{\text {substance1 }} / M_{\text {substance2 }}\right)$ and compared them with the re-

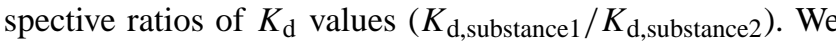
used the distribution coefficients that had been determined in the last soil sample taken before the respective rain event. Figure 8 shows the field data for all experimental substances, all the events with overland flow samples and different experimental fields. In Fig. 8 we also show two lines based on Eq. 2 with the following assumptions: $z=50 \mathrm{~mm}$, $\theta_{\text {sat }}=0.5, \rho=1.2 \mathrm{~g} \mathrm{~cm}^{-3}$ and $q_{\text {mobile }}=10 \mathrm{~mm}$ (dashed line) and $q_{\text {mobile }}=100 \mathrm{~mm}$ (solid line). No dependence can be detected between $M$ ratios and $K_{\mathrm{d}}$ ratios of the field data, and they do not correspond to the expected behaviour expressed in Eq. 2. All $M$ ratios scatter around one. Obviously, the different substances were mobilised into overland flow to a similar degree, independent of their distribution coefficients $K_{\mathrm{d}}$. This implies that the influence of substance properties affected mobilisation in a different manner than expected and/or that other factors were more influential than the apparent equilibrium distribution. 


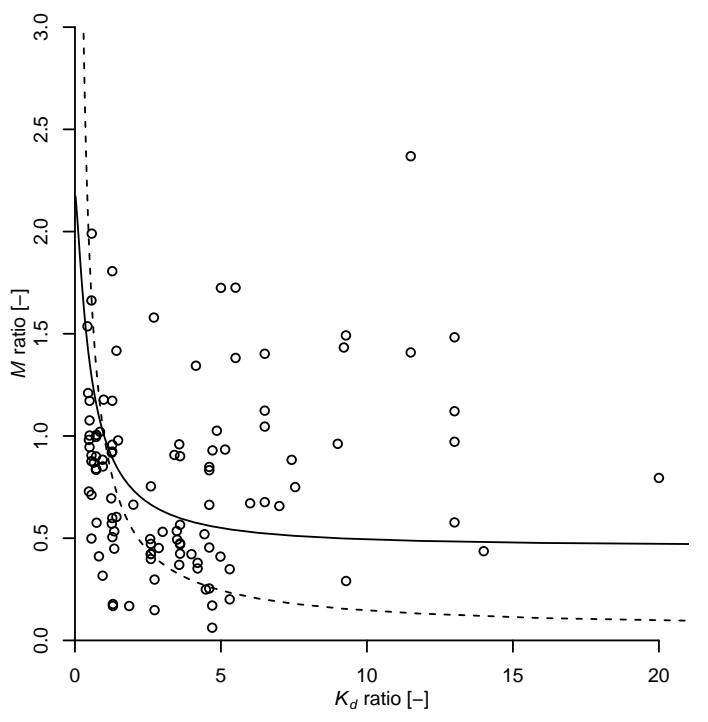

Fig. 8. The ratio of the mobilisation coefficients $M$ of two substances in the same sample, plotted against the respective ratio of distribution coefficients $K_{\mathrm{d}}$ from the corresponding field. Dashed line: SWAT prediction with a flux of $10 \mathrm{~mm}$ of mobile water (see text), solid line: SWAT prediction with a flux of $100 \mathrm{~mm}$ of mobile water.

\subsubsection{Retention during infiltration}

While the field data do not show an influence of substance properties on the mobilisation process, the data suggest that the transport through macropores was affected by sorption. We compared retention coefficients $R$ (Sect. 2.9) of different substances (all applied together on field 1) within the same samples at two time points during event E2. Figure 9 shows the ratios of $R$ of substance pairs plotted against the $K_{\mathrm{d}}$ ratios of the respective substance pairs. The figure reveals that the retention coefficients were larger for substances with higher $K_{\mathrm{d}}$ values. This means that sorption played a role during the fast transport from ponding overland flow through macropores to tile drains. From the compounds dissolved in ponding water, a larger fraction of the stronger sorbing compounds was retained in the soil. This implies that the herbicide load was reduced during the soil passage, even though the flow was fast and the travel time short.

\subsection{Concentration dynamics}

We observed elevated concentrations of all the applied substances in the stream and in tile drains during all of the sampled events. Additionally, we observed that the substances applied to the same fields showed very similar dynamics. Atrazine, S-metolachlor and sulcotrione (the substances on the experimental fields) always peaked at the same time. The same holds for terbuthylazine and mesotrione, which were spayed on the alternative fields. However, the dynamics of these two mixtures differed during most events. Figures 5 and 6 show examples for this behaviour.

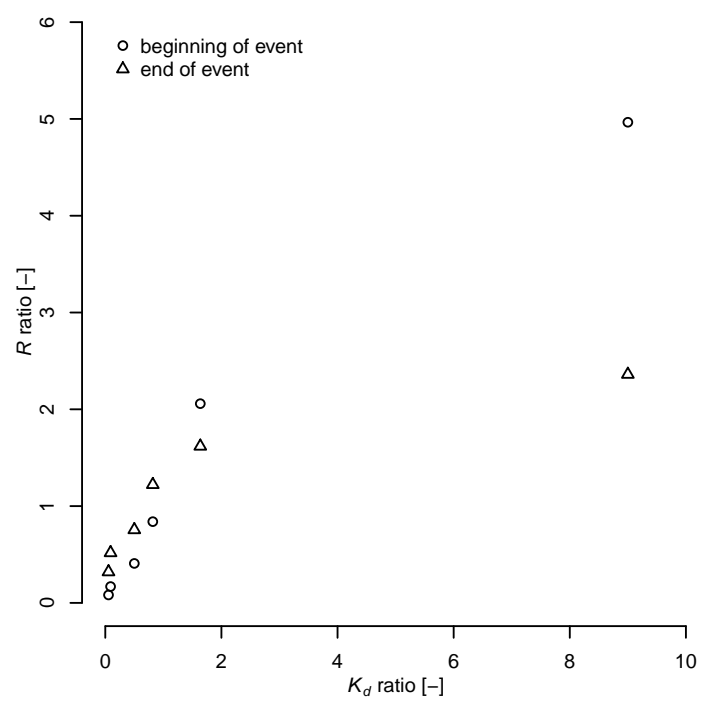

Fig. 9. Ratio of retention coefficients $R$ of two substances plotted against the respective $K_{\mathrm{d}}$ ratio.

Correlation coefficients were calculated for the concentrations during event E2 at the stations $S_{\mathrm{d}}$ and $O_{\mathrm{u}}$ (shown in Figs. 5 and 6). The correlation between atrazine and sulcotrione was 0.90 and 0.95 at the stations $S_{\mathrm{d}}$ and $O_{\mathrm{u}}$, respectively; between atrazine and terbuthylazine it was 0.02 and -0.38 .

The terbuthylazine concentration followed the hydrograph dynamics at station $S_{\mathrm{d}}$ closely (correlation coefficient of 0.71 during event E2). At station $O_{\mathrm{u}}$, some correlation between discharge and terbuthylazine concentration can also be observed (correlation coefficient of 0.47 during event E2, see Figs. 5 and 6). For atrazine and sulcotrione, no correspondence between discharge dynamics and concentration can be observed in Figs. 5 and 6; the correlation between atrazine and discharge during event E2 was -0.20 and -0.45 at the stations $S_{\mathrm{d}}$ and $O_{\mathrm{u}}$, respectively. These data suggest a decoupling of discharge and concentration peaks for atrazine, S-metolachlor and sulcotrione in several events.

Upstream of the two stations $S_{\mathrm{d}}$ and $O_{\mathrm{u}}$, there is no open stream; they have purely subsurface catchments. Nevertheless, we observed rather high herbicide concentrations (Figs. 5 and 6).

\section{Discussion}

\subsection{Transport processes and CSAs}

The differentiation between saturation excess and infiltration excess overland flow at catchment scale is not an easy task. However, the observed groundwater levels and the electrical conductivity of overland flow samples indicate that both infiltration excess and saturation excess overland flow occurred during the study period. The widespread occurrence of overland flow during the events E1 to E12 (Table 1 and Fig. 4), 
when most groundwater levels were low (Table 1), can only be explained with infiltration excess. During the event E13 groundwater levels were high, indicating that saturation excess may have occurred at several locations. Electrical conductivity of the overland flow samples supports this interpretation as follows. Rain typically has a very low electrical conductivity $\left(<50 \mu \mathrm{S} \mathrm{cm}^{-1}\right)$, while groundwater and soil porewater have significantly higher electrical conductivities (baseflow in this catchment has an electrical conductivity around $800 \mu \mathrm{S} \mathrm{cm}^{-1}$ ). Infiltration excess overland flow does not contain any groundwater, and we argue that mixing with soil pore water is limited (Hahn et al., 2012). We therefore expected infiltration excess overland flow to have low conductivity. Areas that produce saturation excess overland flow (groundwater level at the surface) often also produce return flow (exfiltrating groundwater). We therefore expected saturation excess overland flow to consist of a mixture of return flow, pre-event pore water and rain, thus having higher electrical conductivity. The electrical conductivity of overland flow is additionally influenced by easily dissolved substances at the surface, which makes the interpretation more difficult. The electrical conductivities in the overland flow samples show a clear separation between events. Except for events E2 and E13, the average electrical conductivities in the overland flow samples were around $200 \mu \mathrm{S} \mathrm{cm}^{-1}$, while it was above $400 \mu \mathrm{S} \mathrm{cm}^{-1}$ in events E2 and E13. Event E2 was a special case because fertilizer was applied on several fields directly before the event. The high electrical conductivity in the overland flow was probably caused by dissolved fertilizer in this case. Therefore, we concluded that the herbicides were mainly mobilised by infiltration excess overland flow. Only during event E13 was saturation excess overland flow the more important process (Hirzel, 2009). This interpretation is supported by the runoff ratios being low for all events except E13 (> 40\%). This shows that a different runoff regime was active during event E13. Our observation that infiltration excess overland flow is the main transport process for herbicides is in contrast to previous studies in the Swiss Plateau (Leu et al., 2004a, 2010; Gomides Freitas et al., 2008), which indicated that saturation excess overland flow was the dominant process controlling diffuse herbicide pollution.

The differences between these studies are most probably caused by different rainfall characteristics of the events that led to the main herbicide losses. In the studies by Leu et al. (2004a) and Gomides Freitas (2005), the maximum rainfall intensity of the events that led to the main herbicide losses were 3.2 and $2.4 \mathrm{~mm}(15 \mathrm{~min})^{-1}$, respectively. In contrast, the main loss event in this study had a maximum intensity of $12 \mathrm{~mm}(15 \mathrm{~min})^{-1}$ (see Fig. 10 and Table 1). Figure 10 shows the histograms of rain intensities of the months May to July in these three field studies (Leu et al., 2004a; Gomides Freitas, 2005, and this study) together with the 30yr average intensities during these months at Schaffhausen (closest permanent weather station to this study site, Meteoschweiz, 2012). The figure shows that the timing of the
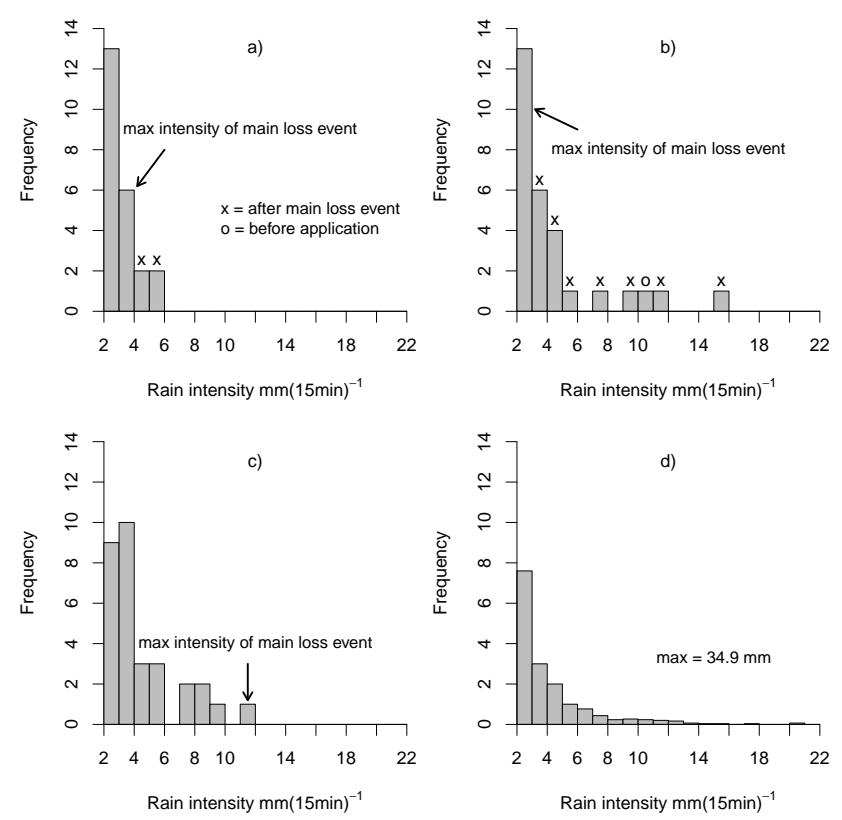

Fig. 10. Comparison of frequencies of rain intensities $>2 \mathrm{~mm}(15 \mathrm{~min})^{-1}$ for the period May to July from (a) the field experiment in 2000 (Leu et al., 2004a), (b) the field experiment in 2003 (Gomides Freitas et al., 2008), (c) this field experiment and (d) the 30-yr average at the permanent weather station in Schaffhausen (Meteoschweiz, 2012).

rain events determined the process that lead to the main herbicide losses. If the first event with a substantial hydrological response after application was a high intensity event, infiltration excess overland flow was dominant, but if it was a low intensity event, saturation excess overland flow dominated the herbicide losses. The histograms also show that none of the field experiment years was an extreme year compared to the 30-yr average. However, high intensities were much more common in 2003 and 2009 than in 2000.

Saturation excess and infiltration excess overland flow are influenced by different site characteristics. While the position in the relief and the subsoil properties play a major role in triggering saturation excess runoff, infiltration excess overland flow is strongly affected by topsoil properties (Lyon et al., 2006; Easton et al., 2008; Gerits et al., 1990). Accordingly, one may expect the two runoff processes to occur in different parts in the landscape. Equation (1) can be re-formulated to take this into consideration:

$A_{\text {CSA }}=\left(A_{\text {source }} \cap A_{\text {inf_ex }} \cap A_{\text {connect }}\right) \cup\left(A_{\text {source }} \cap A_{\text {sat_ex }} \cap A_{\text {connect }}\right)$

This equation states that the CSA extent is an overlay of CSAs with active areas for infiltration excess with those causing saturation excess runoff. As discussed above, the occurrence of the two processes may differ substantially in time, depending on the meteorological conditions. The distinction between the two processes has further implications for CSA management. The risk for pesticide transport by 
infiltration excess overland flow depends on the crop and stage of crop growth at the time of pesticide application. Additionally land management practices play a role for soil surface properties. This makes $A_{\text {inf_ex }}$ very variable in time and hard to predict without very local information on the actual land management. Furthermore, the spatial pattern of infiltration excess overland flow can be dominated by the spatial variability of rain intensity. These disadvantages for the prediction of infiltration excess runoff areas are combined with the advantage that prevention of infiltration excess overland flow is much easier as compared to saturation excess overland flow. Because infiltration excess depends strongly on topsoil properties, it can be influenced by land management and cropping practices. This is much less of an option for saturation excess overland flow, which is strongly controlled by constant site characteristics like the position in the landscape.

The finding that infiltration excess overland flow can be an important process on agricultural land in humid climate is not surprising per se. Other studies have shown this process before (Srinivasan et al., 2002; Church and Woo, 1990; Moore et al., 1976; Deasy et al., 2011). However, most of the work on critical source areas focuses on saturation excess overland flow (e.g. Pionke et al., 2000; Gburek and Sharpley, 1998; Frey et al., 2009; Easton et al., 2008; Lyon et al., 2006). The particularity of this study is that it could show the importance of infiltration excess overland flow for the transport of herbicides to the stream at catchment scale under climate conditions that were characterised by considerable amounts of rain during the application period.

\subsection{Substance properties and transport}

Previous observations have shown that the loss rates of herbicides depended on the $K_{\mathrm{d}}$ values of the substances (lower losses for substances with higher $K_{\mathrm{d}}$, Brown and van Beinum, 2009; Gomides Freitas et al., 2008; Leu et al., 2004a; Louchart et al., 2001) and that the sorption strengths did not affect the timing of concentration peaks (Leu et al., 2004a; Gomides Freitas et al., 2008). Based on these observations, it was concluded that the substance properties of the herbicides have an influence on how much of a compound is mobilised into fast flow, but that these properties do not affect the transport of the compound once it gets into the fast flow component (Leu et al., 2004a; Gomides Freitas et al., 2008). The results observed in this study were the opposite of what we expected: Sorption did not yield any measurable influence on the mobilisation of the compounds into surface runoff (no dependence of $M$ on $K_{\mathrm{d}}$, see Fig. 8), but it did so during the transport by preferential flow towards tile drains ( $R$ depends on $K_{\mathrm{d}}$, see Fig. 9).

These (apparent) contradictions can probably be explained by the different levels of detail during the investigation of transport along the flow paths. In previous work, the interpretation was based on the knowledge of input into and output from the catchments. In this study, we also obtained information along the flow path by sampling ponding water. This more detailed information allows for differentiation between sorption effects during mobilisation and sorption effects during transport.

We expected that substances that sorb more strongly would be mobilised less compared with less sorbing substances. Hence, one can expect that the ratio of the $M$ values of two compounds decreases as a function of the respective $K_{\mathrm{d}}$ ratio. The lack of sorption effect with regard to the mobilisation of the compounds (see Fig. 8) may be caused by the fact that the equilibrium concept behind the $K_{\mathrm{d}}$ values is not adequate to describe the mobilisation of the herbicides from soil to overland flow. Under field conditions following application, pore water and solid phase concentration are barely in equilibrium due to several reasons. Firstly, the equilibrium takes weeks to months to establish for many compounds due to slow kinetic sorption. This is likely for the herbicides studied (e.g. Altfelder et al., 2000; Mamy and Barriuso, 2007; Streck et al., 1995; Zhu and Selim, 2000) and our results showing increasing $K_{\mathrm{d}}$ with time (Sect. 3.2.1 and Fig. S1 in the Supplement) also indicate that slow kinetic sorption takes place. Secondly, a continuous, rather rapid degradation of the compounds and changing soil moisture due to precipitation and evapotranspiration permanently change porewater concentrations in the topsoil. Furthermore, the addition of water for the pore water extraction (see Sect. 2.7.2) can also influence the measured apparent $K_{\mathrm{d}}$ resulting in artifacts of the extraction method. However, the natural porewater in a soil sample taken one day after a rain event is also not in equilibrium with the solid phase. The measured apparent $K_{\mathrm{d}}$ values in the soil samples show a steady increase with time for most of our study fields and substances. They do not seem to be influenced by changing soil moisture or the amount of added water (see Fig. S1 in the Supplement for examples). We are therefore confident that our results are not strongly influenced by methodological artifacts.

Conceptually, a mobilisation of compounds from soil into overland flow can be considered in terms of at least two processes: a displacement of pore water with a certain herbicide concentration at near-equilibrium with the solid phase, and a kinetic desorption of herbicides into infiltrating water at lower concentrations following a chemical potential gradient. It is therefore possible that faster desorption kinetics compensate for lower equilibrium concentrations in water. It was shown that the kinetic sorption of many compounds can be explained with diffusion into organic matter (Brusseau and Rao, 1989). In addition, Villaverde et al. (2009) postulated that sorption kinetics in undisturbed soil aggregates are negatively correlated with sorption strength. With both of these mechanisms (diffusion into organic matter and diffusion into soil aggregates), at a given time, stronger sorbing compounds rather sorb at the surface of organic matter or soil aggregates, while compounds with weaker sorption can diffuse farther into these particles. If diffusion out of organic matter or soil aggregates was the rate limiting step, 
stronger sorbing compounds could have faster desorption kinetics. This could explain our results. Furthermore, it is possible that our soil sampling depth of $5 \mathrm{~cm}$ is not representative for the layer at the surface where mobilisation takes place. Stronger sorbing compounds could be overrepresented in the top layer, compared with our sampling depth. In addition, our substance selection does not cover the full range of sorption strengths. Possibly, the sorption effects during mobilisation were masked by other factors for our substances, but they would become visible for substances that differ more in their sorption properties.

We do not have time-resolved samples of overland flow to directly prove the statement that different desorption kinetics compensate for different equilibrium concentrations as we postulate in the paragraph above. However, different desorption kinetics should still be visible in the concentration dynamics at the stream sampling sites where we do have time-resolved samples. The concentration ratio of a less sorbing substance relative to a stronger sorbing one should increase during the event, because the substance with weaker sorption is mobilised more slowly. This behaviour was indeed observed for sulcotrione and atrazine, where sulcotrione concentration increased relative to atrazine concentration in several events at the sampling sites (see Fig. S2 in the Supplement for an example). Even though the interpretation of our results on herbicide mobilisation remain speculative to some degree, they indicate that equilibrium sorption is not the only relevant process during herbicide mobilisation. The shift in concentraion ratios in the stream demonstrates that pore scale mobilisation processes can result in effects that are visible at catchment scale.

Our results on retention indicate that sorption affected the transport through preferential flow paths to tile drains (Sect. 3.2.3, Fig. 9). This should lead to a retardation of stronger sorbing compounds. However, no retardation was visible in the timing of the peak concentrations. This can have two reasons. Firstly, the water at sampling station $O_{\mathrm{u}}$ was a mixture of several flow components (see Sect. 4.4), whereas the retardation would only appear in the macropore flow originating from the ponding overland flow. The timing of the concentration peak of all substances, however, was determined by the mixing ratio of the flow components; this can mask the retardation occurring in one flow component. Secondly, the travel times were so short that any retardation effects were too subtle to be detected with our temporal sampling scheme.

\subsection{Connectivity}

This study confirmed previous work (Frey et al., 2009; Kiesel et al., 2010; Barron et al., 2011) in demonstrating that only a very small part of the catchment has a direct surface connectivity to the open stream; the largest part of the catchment is connected to topographic depressions within the catchment. One main reason for the low surface connectivity is the moderate topography in the catchments, which is typical for major crop production areas. In areas with more pronounced topography, it is expected that larger areas are directly connected to the stream. Field roads, which are common in crop production regions, also often act as small topographic barriers to overland flow. Figure 4 shows that ponding was often mapped directly alongside field roads as shown earlier by Frey et al. (2009).

However, the road network can also have the opposite effect and can increase connectivity by offering new routes for fast transport (Payraudeau et al., 2009; Ledermann et al., 2010). This holds especially true for Switzerland, where a large percentage of roads have a drainage system conveying runoff water directly to the stream network. For natural catchments it may be sufficient to analyse the topography in order to assess the connectivity to the stream network. For agricultural areas like the Swiss Plateau, such an analysis has to be complemented by information on all anthropogenic interventions affecting the flow paths of water through the catchment. Such interventions may be quite region-specific and difficult to generalize. Our connectivity analysis showed that the area connected to shortcuts is much larger than the area directly connected to the stream (see Sect. 3.1.2). The analysis of the connectivity to shortcuts (see Sect. 2.10.3) is based on the assumption that all the overland flow in the catchment of a shortcut also enters the shortcut, which is a worst-case assumption. Several reasons can prevent overland flow from entering shortcuts: (1) Manholes with closed lids (not intended to collect overland flow) do not collect all the water that reaches them. (2) Small-scale topography around the potential shortcut can divert overland flow in another direction. (3) The rim of manholes can be slightly higher than ground surface and prevent overland flow from entering. Furthermore, overland flow can re-infiltrate on its way to the shortcut. Despite these possible restrictions, several shortcuts (storm drains and maintenance manholes) were observed to be active during the study period (Fig. 4).

Spatial sequences of different processes at different locations also caused transport to the stream, even from fields that did not seem to be connected to the stream in any way. This was observed for experimental field 4, which is not directly connected to the stream and only small parts of the field are potentially connected to shortcuts (see Fig. 2). Furthermore, only one drainage tube crosses a corner of the field, which lies entirely on well drained soils and regosols (Fig. 1). Therefore, we did not expect any herbicides from field 4 to be found in the stream. However, we observed the experimental substances in sampling station $S_{\mathrm{u}}$, where field 4 was the only possible source area. Field observations during and after rain events revealed that overland flow and erosion occurred on field 4, such that the flow including the herbicides was routed off-field to a depression on the neighbouring field, where ponding was observed (see Fig. 4 for observed flow paths and ponding and Fig. 11 for the catchment of the depression). The depression is drained and herbicides reached 


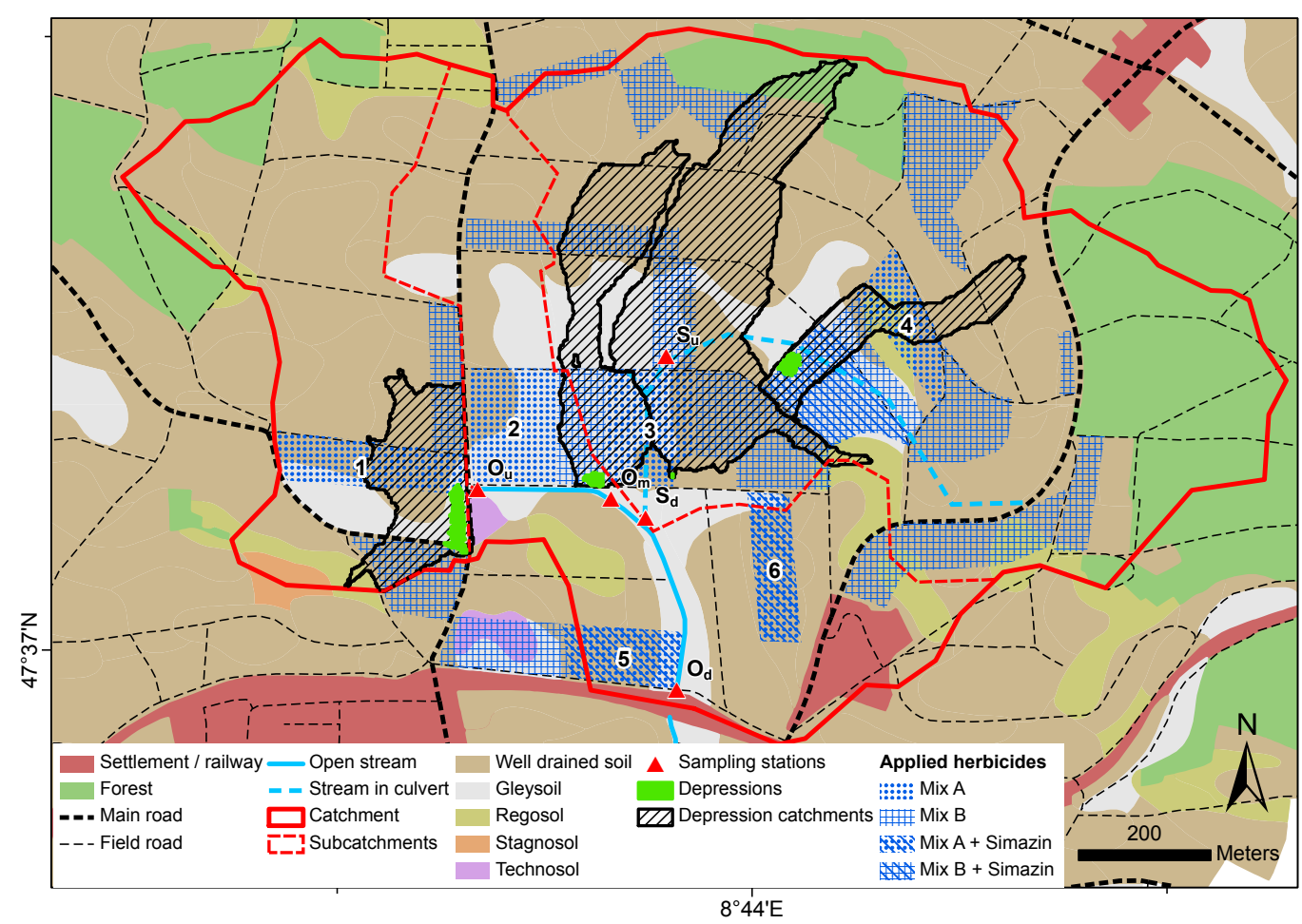

Fig. 11. Map of four major depressions and their corresponding topographic catchments together with the subcatchments of the sampling stations $O_{\mathrm{u}}$ and $S_{\mathrm{d}}$. Sources: Swisstopo (2008); FAL (1997).

the stream via macropore flow to the drainage system (concentration data not shown). This observation implies that the risk for herbicide transport to streams can not be assessed by investigating single fields; fields always have to be seen in their context within the catchment. Fields that are not connected to a stream or shortcut and are not drained can still be contributing areas as shown for experimental field 4 . Furthermore, fields that do not produce overland flow can be affected by run-on from an upslope field as it was shown by Ledermann et al. (2010).

Although most of the fields showed no surface connectivity, herbicides were lost from the fields to the stream network. Obviously, herbicides were transported to the stream even if they were accumulating first in depressions in the landscape. To understand the risk for herbicide losses from different fields, it is important that areas connected to the stream via different pathways do not pose the same risk for losses to the stream. Areas connected via shortcuts are less risky than those directly connected to the stream, because not all of the overland flow might enter the shortcut (see above). Furthermore, areas connected to drained depressions pose an even lower risk because of sorption during the transport to the drainage system (see Sect. 3.2.3). In addition to sorption, the ponding of overland flow in depressions also lowers peak concentrations by retarding the contaminated water. If the contaminated water reaches the stream directly (no ponding), this leads to a sharp concentration peak (see e.g. terbuthylazine in Fig. 5). With ponding, the contaminated water enters the stream more slowly. This leads to elevated concentrations for a longer time but lower peak concentration (see e.g. atrazine in Fig. 5). It has already been shown that drainage water typically has lower concentrations than surface runoff (Brown and van Beinum, 2009; Kladivko et al., 2001). Our findings concerning connectivity suggest that the question whether an area is connected to the stream cannot be answered with yes or no. The question should rather be how well an area is connected to the stream.

\subsection{Concentration dynamics}

The strong correlation of concentration dynamics between compounds applied on the same fields and the missing correlation of concentration dynamics between compounds on different fields (Sect. 3.3) imply that the concentration dynamics were influenced substantially by the spatial origin of the compounds and the flow paths but not by substance properties. Based on previous studies (Gomides Freitas et al., 2008; Leu et al., 2004a,b, 2005) we expected the concentrations to follow the hydrograph dynamics very closely, which was not the case for all substances in this study. In order to understand these chemographs and the apparent contradiction to the observations by Gomides Freitas et al. (2008) and Leu et al. (2004a,b, 2005), one has to consider the relevant flow 
paths that have been observed in this catchment. Based on our results and field observations, we distinguish three major flow components:

1. Surface runoff that entered the stream via shortcuts. This included runoff from roads and farmyards but also overland flow from fields that entered one of the abovementioned shortcuts. This was the fastest flow component; it dominated discharge during times with high rain intensities and its proportion in discharge mainly followed the rain intensity pattern.

2. Macropore flow to tile drains. This water partly consisted of overland flow that ponded in small depressions that are drained; but it also contained water from other sources. This was also a fast flow component that was only active during rain events, but slower and longer lasting than component one.

3. Groundwater flow to tile drains. This was the slowest flow component that made up the base flow and increased with rising ground water tables during rain events. It was characterized by low herbicide concentrations.

The chemograph observed for a given compound was the result of the mixture of these three flow components and their respective herbicide concentrations. The connectivity analysis revealed that not all measuring sites were affected by the first two flow components to the same degree. Only small parts of the experimental fields - receiving atrazine, Smetolachlor and sulcotrione - in the catchment of $S_{\mathrm{d}}$ (fields 3 and 4) for example, were connected to a direct shortcut (see Fig. 2). The largest part of the fields drained into three important depressions (Fig. 11), from where overland flow reached the tile drains via macropore flow (flow component 2). Large areas of alternative corn fields - receiving terbuthylazine were, however, connected to shortcuts (Fig. 2; flow component 1). This led to faster transport and therefore a sharper concentration peak (Fig. 5). Due to the different travel times along the two different fast flow paths, the chemographs of the two herbicide mixtures differed. This interpretation is supported by the electrical conductivity data. Measurements at $S_{\mathrm{d}}$ showed that the terbuthylazine peak occurred simultaneously with lowest electrical conductivity, indicating transport with water that did not travel through soil (Fig. 5). In contrast, atrazine and sulcotrione concentrations peaked at higher electrical conductivity within the event. This was the time of less intense rainfall, where discharge was dominated by the macropore flow from ponding overland flow to the tile drains.

A similar behaviour with less complexity was observed at station $O_{\mathrm{u}}$ (Fig. 6). Only one experimental field (field 1) and two alternative corn fields lie in $O_{\mathrm{u}}$ 's catchment. Experimental field 1 was only connected to the stream via infiltration to the drainage system, direct shortcuts were not present
(Fig. 2). Overland flow from the field was collected in a depression on field 1, where it infiltrated to the drainage system (see Fig. 11 for the catchment of the depression; Fig. 7 shows a picture of this depression). Overland flow originating from the alternative fields in $O_{\mathrm{u}}$ 's catchment (terbuthylazine) could take two flow paths. It either flowed to the depression on field 1 and infiltrated to the drainage system or it could enter the stream via storm drains for road runoff (Figs. 2 and 11). Figure 6 shows that the concentration of the experimental substances (atrazine and sulcotrione) again correlated well with the electrical conductivity in the stream during the event. Directly upstream of this sampling station, the road runoff from the main road in the west of the catchment enters the stream. Discharge peaks were therefore dominated by road runoff, which led to strong dilution of herbicide concentration and to low electrical conductivities during times with intense rainfall. Again, the concentration dynamics clearly supported the connectivity analysis; both indicated transport via infiltration to the drainage system for the experimental substances atrazine and sulcotrione. The terbuthylazine concentration dynamics reflected the two possible flow paths: the very fast pathway via storm drains for road runoff (concentration peak simultaneous with first discharge peak and no significant dilution in second discharge peak at day 8, 00:00 LT) and the pathway via infiltration to the drainage system (elevated concentration at times of low discharge during the event). The resulting concentration dynamics of terbuthylazine was an overlay of the two processes. However, as soon as groundwater flow into the drains dominated discharge (at the end of the event and in base flow periods), the concentrations of all substances were low and no longer correlated with the electrical conductivity.

\section{Conclusions}

This catchment-scale experiment aimed at improving the process understanding of herbicide transport from the fields of application to first-order streams. This was achieved by controlling the herbicide input in an experimental way, simultaneously analysing samples along the entire pathway of herbicide transport from the field to the stream (soil samples, overland flow samples, samples from drainage tubes and the open stream) and monitoring a variety of hydrological state variables. This combination of observations was crucial for improving the process understanding. We could show that most of the catchment is not connected to the stream at the surface, but herbicides were transported to the stream via man-made structures which considerably increased connectivity. Our findings on the role of compound properties for mobilisation and transport of herbicides contradict common concepts to some degree. The study also showed that infiltration excess overland flow can be relevant for the transfer of herbicides under humid climate. 
Our findings also have implications for mitigation measures against diffuse herbicide pollution. One of these measures is based on the concept of contributing areas (CSA) and aims at targeting measures to those parts of a catchment that contribute the main part of the pollution. This concept relies on the temporal stability of the spatial extent of CSAs, which is a reasonable assumption for saturation excess runoff. The spatial occurrence of infiltration excess overland flow may, however, vary substantially through time due to e.g. crop growth and land management. Although the CSA concept may still be a useful heuristic for analysing transport in such situations, it will be more difficult to apply in practice. However, the risk for infiltration excess runoff can be relatively easily mitigated by adapting land management or crop rotations.

The observations in this study suggest that the mobilisation process may be less affected by sorption than expected, whereas herbicides were partially retained during the fast transport through preferential flow paths underneath a depression with ponding water. This improved process understanding is not only of scientific interest but also indicates that hydraulic shortcuts should be avoided in practice. Land management should aim at a soil passage for all water before it enters the stream.

\section{Supplementary material related to this article is available online at: http://www.hydrol-earth-syst-sci.net/ 16/1947/2012/hess-16-1947-2012-supplement.pdf.}

Acknowledgements. Many people have contributed to this study. The field work would not have been possible without Ivo Strahm, Luca Winiger, Marcel Gay and Hans Wunderli. We also want to acknowledge the local farmers for their cooperation and Gabriel Popow for the support in organising the herbicide application. Comments by Christian Leu, Jan Seibert, Irene Wittmer, Heinz Singer, Sebastian Huntscha, Emma Schymanski, Julian Klaus and one anonymous referee significantly improved the quality of the manuscript. We gratefully acknowledge the funding by the Swiss Federal Office for the Environment (FOEN).

Edited by: E. Zehe

\section{References}

Altfelder, S., Streck, T., and Richter, J.: Nonsingular sorption of organic compounds in soil: The role of slow kinetics, J. Environ. Qual., 29, 917-925, 2000.

Anderson, M. G. and Burt, T. P.: Toward more detailed field monitoring of variable source areas, Water Resour. Res., 14, 11231131, 1978.

Aurousseau, P., Gascuel-Odoux, C., Squividant, H., Trepos, R., Tortrat, F., and Cordier, M. O.: A plot drainage network as a conceptual tool for the spatial representation of surface flow pathways in agricultural catchments, Comput. Geosci., 35, 276-288, 2009.
Barron, O. V., Pollock, D., and Dawes, W.: Evaluation of catchment contributing areas and storm runoff in flat terrain subject to urbanisation, Hydrol. Earth Syst. Sci., 15, 547-559, doi:10.5194/hess-15-547-2011, 2011.

Betson, R. P.: What is watershed runoff, J. Geophys. Res., 69, 15411552, 1964.

Brown, C. D. and van Beinum, W.: Pesticide transport via subsurface drains in Europe, Environ. Pollut., 157, 3314-3324, 2009.

Brusseau, M. L. and Rao, P. S. C.: The influence of sorbate-organic matter interactions on sorption nonequilibrium, Chemosphere, 18, 1691-1706, 1989.

Camenzuli, L.: Degradation of herbicides in soils, kinetics and limiting factors in field and laboratory, Master Thesis, Swiss Federal Institute of Technology (ETH), Zürich, Switzerland, 2010.

Carluer, N. and De Marsily, G.: Assessment and modelling of the influence of man-made networks on the hydrology of a small watershed: implications for fast flow components, water quality and landscape management, J. Hydrol., 285, 76-95, 2004.

Church, M. and Woo, M. K.: Geography of surface runoff: some lessons for research, in: Process studies in hillsope hydrology, edited by: Anderson, M. G. and Burt, T. P., Wiley, Chichester, 299-326, 1990.

Deasy, C., Baxendale, S. A., Heathwaite, A. L., Ridall, G., Hodgkinson, R., and Brazier, R. E.: Advancing understanding of runoff and sediment transfers in agricultural catchments through simultaneous observations across scales, Earth Surf. Proc. Land., 36, 1749-1760, 2011.

Descroix, L., Viramontes, D., Estrada, J., Barrios, J. L. G., and Asseline, J.: Investigating the spatial and temporal boundaries of Hortonian and Hewlettian runoff in Northern Mexico, J. Hydrol., 346, 144-158, 2007.

Dunne, T. and Black, R. D.: Partial area contributions to storm runoff in a small New-England watershed, Water Resour. Res., 6, 1296-1311, 1970.

Easton, Z. M., Fuka, D. R., Walter, M. T., Cowan, D. M., Schneiderman, E. M., and Steenhuis, T. S.: Re-conceptualizing the soil and water assessment tool (SWAT) model to predict runoff from variable source areas, J. Hydrol., 348, 279-291, 2008.

FAL: Bodenkarte Kanton Zürich 1:5000, Eidgenössische Forschungsanstalt für Agrarökologie und Landbau Zürich, 1997.

Flühler, H., Durner, W., and Flury, M.: Lateral solute mixing processes - a key for understanding field-scale transport of water and solutes, Geoderma, 70, 165-183, 1996.

Freeze, R. A.: Streamflow generation, Rev. Geophys., 12, 627-647, 1974.

Frey, M. P., Schneider, M. K., Dietzel, A., Reichert, P., and Stamm, C.: Predicting critical source areas for diffuse herbicide losses to surface waters: role of connectivity and boundary conditions, J. Hydrol., 365, 23-36, 2009.

Gburek, W. J. and Sharpley, A. N.: Hydrologic controls on phosphorus loss from upland agricultural watersheds, J. Environ. Qual., 2, 267-277, 1998.

Gemeinde Ossingen: Drainagenkarte 1:1000, Flurgenossenschaft Gemeinde Ossingen, 1995.

Gemeinde Ossingen: Entwässerungsplan der Gemeinde Ossingen, 2008. 
Gerits, J. J. P., de Lima, J. L. M. P., and van den Broek, T. M. W.: Overland flow and erosion, in: Process studies in hillsope hydrology, edited by: Anderson, M. G. and Burt, T. P., Wiley, Chichester, 173-214, 1990.

Gomides Freitas, L.: Herbicide losses to surface waters in a small agricultural catchment, Ph.D. thesis, Swiss Federal Institute of Technology, Zürich (ETH), 2005.

Gomides Freitas, L., Singer, H., Müller, S. R., Schwarzenbach, R. P., and Stamm, C.: Source area effects on herbicide losses to surface waters - a case study in the Swiss Plateau, Agr. Ecosyst. Environ., 128, 177-184, 2008.

Goodrich, D. C., Lane, L. J., Shillito, R. M., Miller, S. N., Syed, K. H., and Woolhiser, D. A.: Linearity of basin response as a function of scale in a semiarid watershed, Water Resour. Res., 33, 2951-2965, 1997.

Hahn, C., Prasuhn, V., Stamm, C., and Schulin, R.: Phosphorus losses in runoff from manured grassland of different soil $\mathrm{P}$ status at two rainfall intensities, Agr. Ecosyst. Environ., 153, 65-74, 2012.

Heathwaite, A. L., Quinn, P. F., and Hewett, C. J. M.: Modelling and managing critical source areas of diffuse pollution from agricultural land using flow connectivity simulation, J. Hydrol., 304, 446-461, 2005.

Herschy, R. W.: Streamflow measurement, 2nd Edn., E\&FN Spon, London, 1995.

Hirzel, G.: Detecting and measuring overland flow in the "Eschibach" catchment, Ossingen, Switzerland, Master Thesis, Swiss Federal Institute of Technology (ETH), Zürich, Switzerland, 2009.

Horton, R. E.: The role of infiltration in the hydrologic cycle, EOS T. Am. Geophys. Un., 14, 446-460, 1933.

Jarvis, N. J.: A review of non-equilibrium water flow and solute transport in soil macropores: Principles, controlling factors and consequences for water quality, Eur. J. Soil Sci., 58, 523-546, 2007.

Kiesel, J., Fohrer, N., Schmalz, B., and White, M. J.: Incorporating landscape depressions and tile drainages of a Northern German lowland catchment into a semi-distributed model, Hydrol. Process., 24, 1472-1486, 2010.

Kirkby, M. J., Callan, J., Weyman, D., and Wood, J.: Measurement and modeling of dynamic contributing areas in very small catchments, Working paper 167, School of Geography, University of Leeds, Leeds, England, 1976.

Kladivko, E. J., Brown, L. C., and Baker, J. L.: Pesticide transport to subsurface tile drains in humid regions of North America, Crit. Rev. Env. Sci. Tec., 31, 1-62, 2001.

Ledermann, T., Herweg, K., Liniger, H. P., Schneider, F., Hurni, H., and Prasuhn, V.: Applying erosion damage mapping to assess and quantify off-site effects of soil erosion in Switzerland, Land Degrad. Dev., 21, 353-366, 2010.

Leu, C., Singer, H., Stamm, C., Müller, S. R., and Schwarzenbach, R. P.: Simultaneous assessment of sources, processes, and factors influencing herbicide losses to surface waters in a small agricultural catchment, Environ. Sci. Technol., 38, 3827-3834, $2004 \mathrm{a}$.

Leu, C., Singer, H., Stamm, C., Müller, S. R., and Schwarzenbach, R. P.: Variability of herbicide losses from 13 fields to surface water within a small catchment after a controlled herbicide application, Environ. Sci. Technol., 38, 3835-3841, 2004 b.
Leu, C., Singer, H., Müller, S. R., Schwarzenbach, R. P., and Stamm, C.: Comparison of atrazine losses in three small headwater catchments, J. Environ. Qual., 34, 1873-1882, 2005.

Leu, C., Schneider, M. K., and Stamm, C.: Estimating catchment vulnerability to diffuse herbicide losses from hydrograph statistics, J. Environ. Qual., 39, 1441-1450, 2010.

Liess, M. and Schulz, R.: Linking insecticide contamination and population response in an agricultural stream, Environ. Toxicol. Chem., 18, 1948-1955, 1999.

Louchart, X., Voltz, M., Andrieux, P., and Moussa, R.: Herbicide transport to surface waters at field and watershed scales in a Mediterranean vineyard area, J. Environ. Qual., 30, 982-991, 2001.

Lyon, S. W., McHale, M. R., Walter, M. T., and Steenhuis, T. S.: The impact of runoff generation mechanisms on the location of critical source areas, J. Am. Water Resour. As., 42, 793-804, 2006.

Mamy, L. and Barriuso, E.: Desorption and time-dependent sorption of herbicides in soils, Eur. J. Soil Sci., 58, 174-187, 2007.

Moore, T. R., Dunne, T., and Taylor, C. H.: Mapping runoffproducing zones in humid regions, J. Soil Water Conserv., 31, 160-164, 1976.

Neitsch, S., Arnold, J., Kiniry, J., and Williams, J.: Soil and water assessment tool theoretical documentation. Version 2005, Tech. Rep., Texas Water Resource Institute, Temple, Texas, 2005.

Noll, M. R. and Magee, E. A.: Quantification of phosphorus sources to a small watershed: a case study of Graywood Gully, Conesus Lake, NY, J. Great Lakes Res., 35, 50-55, 2009.

Payraudeau, S., Junker, P., Imfeld, G., and Gregoire, C.: Characterizing hydrological connectivity to identify critical source areas for pesticides losses, 18th World Imacs Congress and Modsim09 International Congress on Modelling and Simulation, 13 to 17 July 2009, Cairns, Australia, 1879-1885, 2009.

Pionke, H. B., Gburek, W. J., Sharpley, A. N., and Schnabel, R. R.: Flow and nutrient export patterns for an agricultural hill-land watershed, Water Resour. Res., 32, 1795-1804, 1996.

Pionke, H. B., Gburek, W. J., and Sharpley, A. N.: Critical source area controls on water quality in an agricultural watershed located in the Chesapeake Basin, Ecol. Eng., 14, 325-335, 2000.

PPDB: The PPDB (Pesticide Properties DataBase), collated by the University of Hertfordshire, 2010.

Singer, H., Jaus, S., Hanke, I., Lück, A., Hollender, J., and Alder, A. C.: Determination of biocides and pesticides by online solid phase extraction coupled with mass spectrometry and their behaviour in wastewater and surface water, Environ. Pollut., 158, 3054-3064, 2010.

Srinivasan, M. S., Wittman, M. A., Hamlett, J. M., and Gburek, W. J.: Surface and subsurface sensors to record variable runoff generation areas, T. ASAE, 43, 651-660, 2000.

Srinivasan, M. S., Gburek, W. J., and Hamlett, J. M.: Dynamics of stormflow generation - a hillslope-scale field study in eastcentral Pennsylvania, USA, Hydrol. Process., 16, 649-665, 2002.

Stamm, C., Sermet, R., Leuenberger, J., Wunderli, H., Wydler, H., Flühler, H., and Gehre, M.: Multiple tracing of fast solute transport in a drained grassland soil, Geoderma, 109, 245-268, 2002.

Stamm, C., Waul, C., Leu, C., Freitas, L. G., Popow, G., Singer, H., and Müller, S.: Sorption effects on herbicide losses to surface waters in a small catchment of the Swiss Plateau, Zeitschrift für Pflanzenkrankheiten und Pflanzenschutz, J. Plant Dis. Protect, 19, 951-958, 2004. 
Streck, T., Poletika, N. N., Jury, W. A., and Farmer, W. J.: Description of simazine transport with rate-limited, two-stage, linear and nonlinear sorption, Water Resour. Res., 31, 811-822, 1995.

Swisstopo: DTM ${ }^{\complement}$, reproduced with permission of swisstopo, Wabern, Switzerland, JA100119, 2003.

Swisstopo: Geologischer Atlas der Schweiz ${ }^{\complement}$, reproduced with permission of swisstopo, Wabern, Switzerland, JA100119, 2007.

Swisstopo: Vector $25^{\circledR}$, reproduced with permission of swisstopo, Wabern, Switzerland, JA100119, 2008.

Thurman, E. M., Goolsby, D. A., Meyer, M. T., and Kolpin, D. W.: Herbicides in surface waters of the Midwestern United-States the effect of spring flush, Environ. Sci. Technol., 25, 1794-1796, 1991.

Vereecken, H., Vanderborght, J., Kasteel, R., Spiteller, M., Schäffer, A. and Close, M.: Do lab-derived distribution coefficient values of pesticides match distribution coefficient values determined from column and field-scale experiments? A critical analysis of relevant literature, J. Environ. Qual., 40, 879-898, 2011.
Villaverde, J., Van Beinum, W., Beulke, S., and Brown, C. D.: The kinetics of sorption by retarded diffusion into soil aggregate pores, Environ. Sci. Technol., 43, 8227-8232, 2009.

Weiler, M. and Naef, F.: Simulating surface and subsurface initiation of macropore flow, J. Hydrol., 273, 139-154, 2003.

Wittmer, I. K., Bader, H. P., Scheidegger, R., Singer, H., Lück, A., Hanke, I., Carlsson, C., and Stamm, C.: Significance of urban and agricultural land use for biocide and pesticide dynamics in surface waters, Water Resour. Res., 44, 2850-2862, 2010.

Zhu, H. X. and Selim, H. M.: Hysteretic behavior of metolachlor adsorption-desorption in soils, Soil Sci., 165, 632-645, 2000. 